A NEW SYSTEM FOR

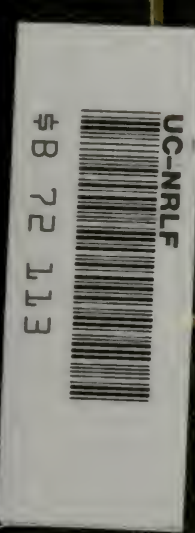

PREVENTING

COLLISTONS

AT SEA 


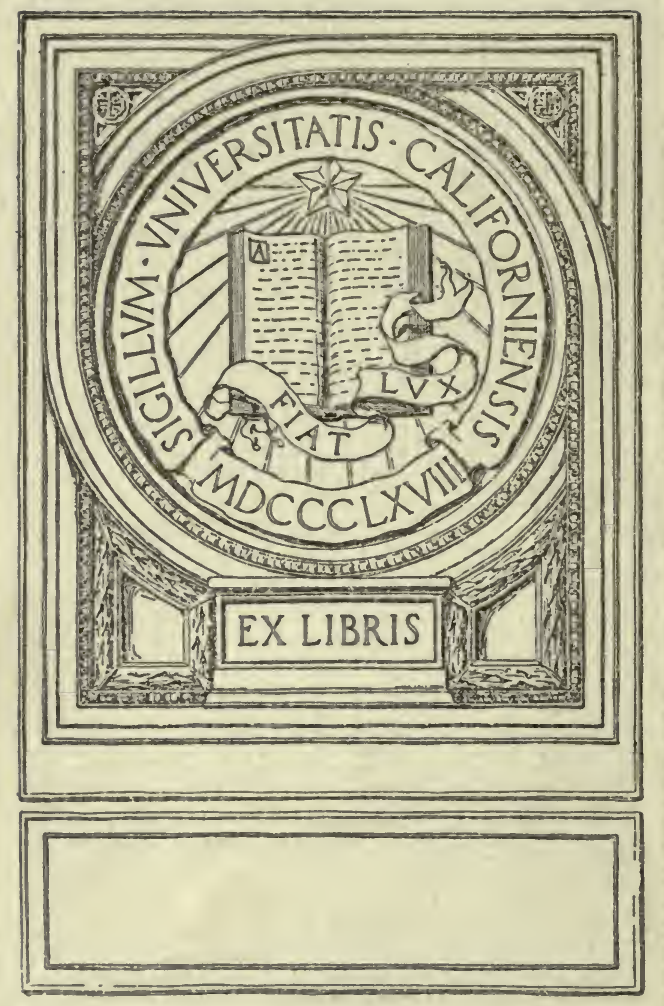



Digitized by the Internet Archive in 2007 with funding from Microsoft Corporation 
A NEW SYSTEM FOR

PREVENTING COLLISIONS AT SEA 



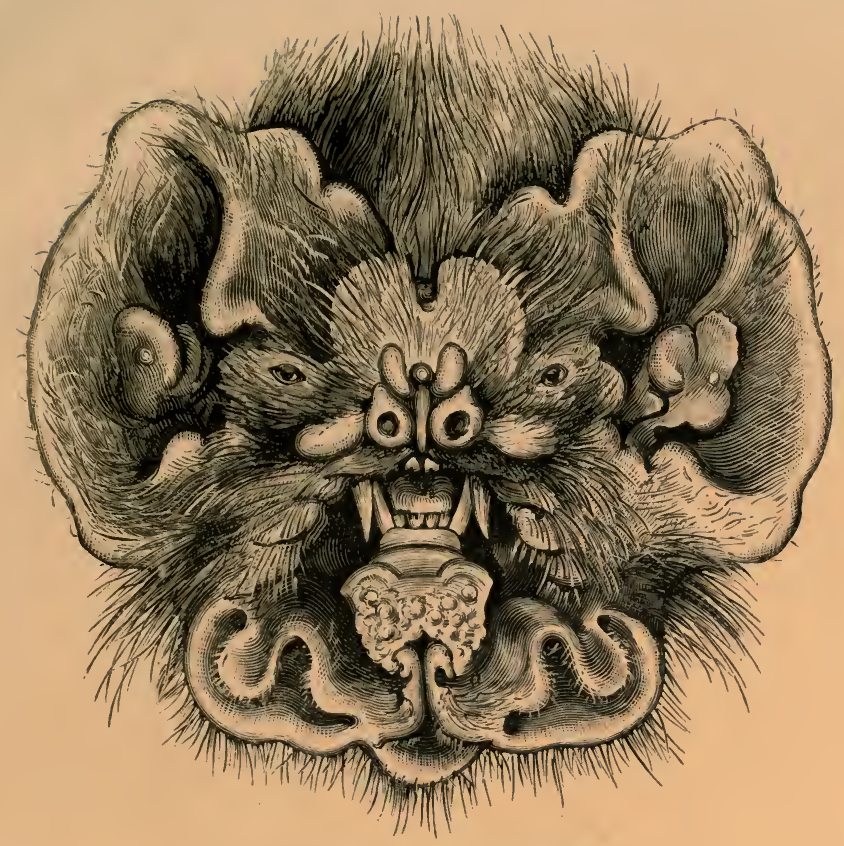

HEAD OF BLAINVILLE'S BAT.

Some have suggested that the alleged sixth sense of the Bat is nothing more nor less than the sense of feeling. To a certain extent this is true, but the same thing can be said of every sense that we possess.

The Bat has an organ that we do not have which enables it to get a very fair idea of its surroundings without the use of either ears or eyes. This organ is peculiar to itself, and does not resemble any other known organ of sense.

A bird certainly has the sense of feeling highly developed, but it is quite helpless if deprived of its eyes, whereas experiments show that all Bats which possess the organ of the sixth sense do just as well without eyes as with them. This sense is certainly quite distinct from that of seeing or hearing; therefore are we not justified in designating it as "The Sixth Sense"?

Measures have already been taken for securing Patents in the leading countries of the world on the apparatus, devices, and mode of operation shown in this pamphlet.

HIRAM S. MAXIM.

London, June, I9I 2. 
औ 
- 


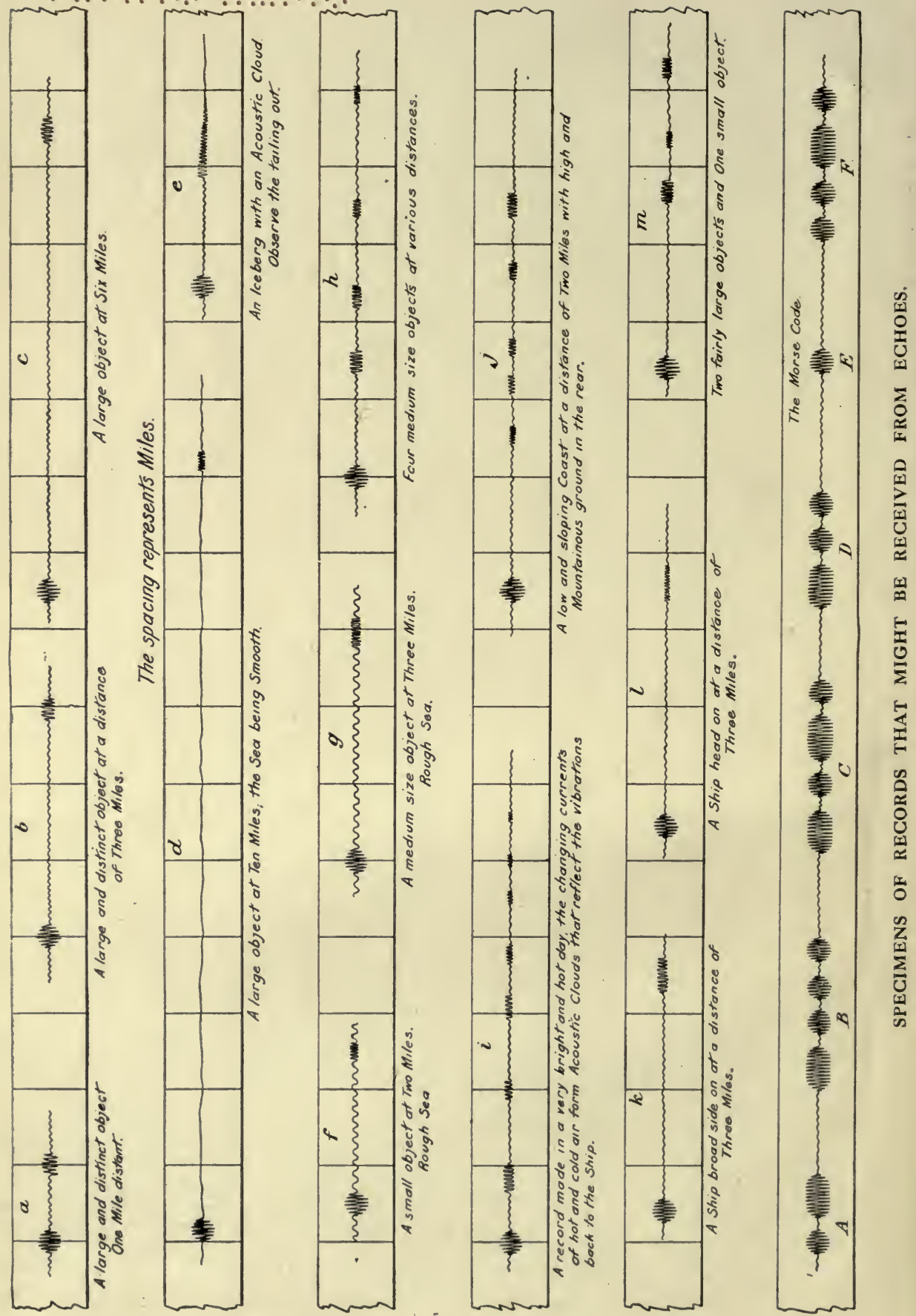




\section{A NEW SYSTEM \\ FOR PREVENTING COLLISIONS AT SEA}

BY

SIR HIRAM S. MAXIM

PRINTED FOR THE AUTHOR BY CASSELL AND COMPANY, LIMITED London, New York, Toronto and Melbourne 1912 


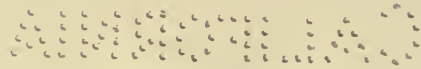

$\checkmark K 311$

$M^{3}$

ALL RIGHTS RESERVED 


\section{GONTENTS}

INTRODUCTION •

A New System for Preventing Collisions at SEA . . . . . . . . . . I

A Sixth Sense .

The Application of the Sixth Sense to Ships . 22

Some Remarks on the Operation and Use of THE ApPaRATUS . . . . . . . 26

ICEBERGS $\quad . \quad+\quad \cdot \quad \cdot \quad \cdot \quad \cdot \quad \cdot \quad 43$ 



\section{LIST OF ILLUSTRATIONS}

Specimens of Records that might be received from Echoes

Frontispiece

PAGE

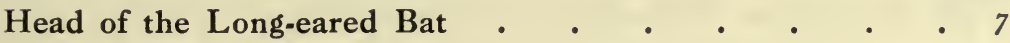

Head of the African Magaderm . . . . . 7

Head of the Lyre Bat (Hilarious Bat) . . . . - 8

Head of the Mourning Horseshoe Bat . . . . 8

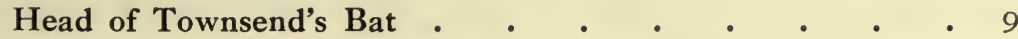

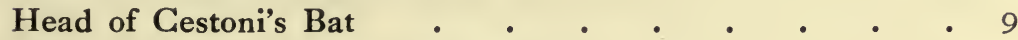

Head of the Speckled Vampire Bat . . . . . Io

Head of the Lesser Horseshoe Bat . . . . . . Io

The Barbastelle . . . . . . . . . . Io

Mouth of the Spectacled Stenoderm . . . . . II

The Trident Bat . . . . . . . . . . II

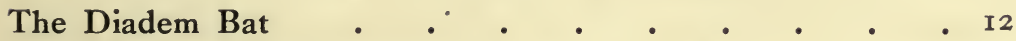

Head of the Greater Horseshoe Bat • . . • . I2

Head of the Collared Bat . . . . . . . . I3

Head of Blainville's Bat • . . . . . . . 13

Head of the True Vampire Bat . . . . . . I4 $_{4}$

Head of the Grey Fruit Bat . . . . . . . I4

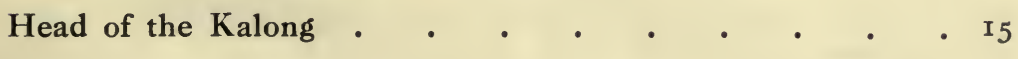




\section{List of Illustrations}

Welwitsch's Bat . . . . . . . . . . . . 16

Plate 1.-Vertical Central Section of the Apparatus for Producing the Vibrations . . . . . . . 36

Plate 2.-Side Elevation of the Siren or Vibrator . • . 37

Plate 3.-Receiver that Makes and Breaks Electrical Gircuits for Ringing Bells . . . . . . . . . 39

Plate 4.-Receiver for Recording the Vibrations . . 40

Plate 5. - System of Mounting the Receivers . . . . $4^{\mathrm{I}}$

Iceberg in the South Pacific . . . . . . . 44 


\section{INTRODUCTION}

THE sinking of the Titanic, although the greatest catastrophe of the kind, is by no means an isolated case. Many other large ships have been destroyed or lost at sea, some of them having disappeared without leaving the least trace of what had happened to them, but the number of ships, though very considerable, which have been lost in the open sea by collisions with other ships or with icebergs, is extremely small in comparison with those which have been lost by running on to rocks or running ashore in a fog. I have seen a chart called the "Caviare" map, in which a little black dot represents the locality where a ship has been lost, and these little black dots are so numerous about the coasts of England, Ireland, Norway, Sweden and Denmark as to give the map the appearance of a lot of caviare, consequently the name.

Professor John Tyndall, "the poet of science," was instructed by the British Government to conduct certain experiments with the view of obtaining the best means of preventing ships from running ashore in a fog. After a great number of lights, electrical and otherwise, had been tried with very indifferent success, experiments were made with sound-producing instruments, such as very large steam whistles, enormous trumpets worked with compressed air, and a siren specially constructed for fog-signalling and much used in the United States. Guns were also used of various sizes and with varying 


\section{Introduction}

charges. In some cases, the sound of the guns travelled farther than that of any other instrument; in some cases the trumpet and siren were about equal, but in most cases the siren did the best. But there is something besides carrying power in the siren which makes it eminently well qualified for sending out powerful vibrations and receiving back the echo.

Professor Tyndall tells us not only that the reflection of sound from a solid body like a ship is very great, but also that he got astonishing results from acoustic and invisible clouds :

"On the 17 th of October, at about 5 p.m., the air being perfectly free from cloud, we rowed towards the Foreland, landed, and passed over the seaweed to the base of the cliff. As I reached the base the position of the Galatea was such that an echo of astonishing intensity was sent back from her side; it came as if from an independent source of sound established on board of the steamer. This ceased suddenly, leaving the aerial echoes to die away gradually in silence."

On some occasions the learned professor was greatly puzzled. Sometimes at a distance of three miles he was quite unable to hear the report of the guns or the sound of the whistles or sirens, while on other days these could be heard at a distance of nine or ten miles. On one occasion they drew up as near as two and a half miles to the shore and still the sounds were inaudible. Suddenly a cloud obscured the sun, a dark shadow overspread the sea; then every instrument was heard, and, while the cloud was still obscuring the sun, they withdrew to a distance of six miles and practically all the instruments were heard.

On another day while experimenting, the air was opticxii 


\section{Introduction}

ally clear, not the least sign of 'a cloud in sight and the sun was shining down with merciless intensity, making everything hot that it struck. There was very little wind. Under these conditions all the instruments were inaudible at a distance of two miles.

It then occurred to the Professor that there was an acoustic cloud between the instruments and the ship, and he reasoned it out in this way: when the sun shines on an ordinary cloud, the cloud refuses passage to the light; the light is broken up and numerous reflections take place; the light is not all lost-some of it is reflected. The side of a cloud that the sun shines on is very bright; why, then, should there not be a similar result from an invisible acoustic cloud? The immense energy of the sound sent out must go somewhere; if the cloud refuses its passage, would it not be sent off in the other direction? Would it not be reflected back as is the case with light on a common cloud? As he could get no response from the sound sent out, he thought he would see what he could obtain from the other side of the cloud. I quote the following:-

"It is incredible that so great a body of sound could utterly disappear in so short a distance without rendering some account of itself. Supposing, then, instead of placing ourselves behind the acoustic cloud we were to place ourselves in front of it, might we not, in accordance with the law of conservation, expect to receive by reflection the sound which had failed to reach us by transmission? The case then would be strictly analogous to the reflection of light from an ordinary cloud to an observer between it and the sun.

"My first care in the early part of the day in question was to assure myself that our inability to hear the sound did not arise from any derangement of the instruments on shore. Accompanied by Mr. Price Edwards at I p.m., I was rowed to the shore, and xiii 


\section{Introduction}

landed at the base of the South Foreland cliff. The body of air which had already shown such extraordinary power to intercept the sound, and which manifested this power still more impressibly later in the day, was now in front of us. On it the sonorous waves impinged, and from it they were sent back with astonishing intensity. The instruments, hidden from view, were on the summit of the cliff 235 feet above us, the sea was smooth and clear of ships, the atmosphere was without a cloud, and there was no object in sight which could possibly produce the observed effect. From the perfectly transparent air the echoes came, at first with a strength apparently little less than that of the direct sound, and then dying away."

Professor Tyndall shows the necessity of using soundproducing instruments in foggy weather instead of attempting to penetrate the fog with a light :-

"The cloud produced by the puff of a locomotive can quench the rays of the noonday sun; it is not therefore surprising that in dense fogs our most powerful coast lights, including even the electric light, should become useless to the mariner.

"Disastrous shipwrecks are the consequence. During the ten years ending in 1874 , no less than 273 vessels were reported as totally lost on our own coast in fog or thick weather. The loss, I believe, is far greater on the American seaboard."

It is a curious and interesting fact that anything in the nature of a light does best in perfectly clear weather, while anything in the nature of a sound does best in thick or foggy weather. Acoustic clouds that bar the passage of sound never exist in foggy weather; these clouds are produced by numerous conflicting currents of air at different densities caused by the interchange of the hot air from below with the cold air from above, and this action never takes place in thick weather; therefore, acoustic clouds cannot interfere with the working of my apparatus. 


\section{Introduction}

Although I do not propose to send out vibrations that can be considered as sound from a musical standpoint, being too low to appeal to the human ear, still, as these atmospheric waves or vibrations only differ from audible sound vibrations in their length, or, in other words, there are less of them in a given time, and as they obey all the laws that govern sound, I propose to treat them as sound and to designate them as sound, although they are not audible to the human ear.

The siren furnished to Professor Tyndall by the United States Government had a rotating disc 5 inches in diameter. The trumpet was sixteen feet long, and the mouth measured 26 inches in diameter. It used steam at $70 \mathrm{lbs}$. pressure to the square inch, and gave off an audible note. The probabilities are that when the steam valve was wide open the power represented would not be more than 50 h.p.

On our large steamships, we very often have a boiler pressure of $280 \mathrm{lbs}$. to the square inch. Suppose, now, that we use a rotating disc 10 inches in diameter and a trumpet correspondingly large, we can convert 500 h.p. into sound, sending out vibrations of enormous energy and amplitude, which ought to travel over a distance very much greater than would be possible with any of the instruments employed by Professor Tyndall. As the steam valve of a siren is only open for about a second at a time, it is very evident that the total amount of steam consumed would not be very great, although the energy when it was actually escaping might be 500 h.p. 



\section{A NEW SYSTEM FOR PREVENTING COLLISIONS AT SEA}

THE wreck of the Titanic was a severe and painful shock to us all; many of us lost friends and acquaintances by this dreadful catastrophe. I asked myself: "Has Science reached the end of its tether? Is there no possible means of avoiding such a deplorable loss of life and property? Thousands of ships have been lost by running ashore in a fog, hundreds by collisions with other ships or with icebergs, nearly all resulting in great loss of life and property."

At the end of four hours it occurred to me that ships could be provided with what might be appropriately called a sixth sense, that would detect large objects in their immediate vicinity without the aid of a searchlight.

Much has been said, first and last, by the unscientific of the advantages of a searchlight. Collisions as a rule take place in a fog, and a searchlight is worse than useless even in a light haze, because it illuminates the haze, making all objects beyond absolutely invisible.

Some have even suggested that a steam whistle or siren might be employed that would periodically give off an extremely powerful sound, that is, a veritable blast, an earpiercing shriek, and then one is supposed to listen for an echo, it being assumed that if any object should be near, a small portion of the sound would be reflected back to the ship, but 


\section{A New System for Preventing Collisions at Sea}

this plan when tried proved an absolute failure. The very powerful blast given off by the instrument is extremely painful to the ears and renders them incapable of hearing the very feeble echo which is supposed to occur only a few seconds later. Moreover, sirens or steam whistles of great power are extremely objectionable on board passenger ships; they annoy the passengers and render sleep impossible. It is, therefore, only too evident that nothing in the way of a light or noise producing apparatus could be of any use whatsoever. 


\section{A SIXTH SENSE}

ALL warm-blooded animals, including Man, are provided with five senses, i.e. seeing, hearing, tasting, feeling, smelling. I now propose to show that there are certain kinds of animals which have a sixth sense, and that with this sixth sense they are perfectly able to detect objects in their vicinity, to determine their character, and to move about with great rapidity and perfect ease when deprived of both sight and hearing, thus proving most conclusively that they possess a sixth sense. I also propose to show that by mechanical means, we can provide a ship with a similar sense, not, of course with the wonderful sensitiveness found in nature, but sufficiently sensitive to detect any large object in the vicinity of the ship, to indicate with a great degree of nicety its distance from the ship, and also to give a fair idea of its size and character.

Before explaining this apparatus, I propose to prove that a certain animal does have a sixth sense.

We are able to see perfectly in twilight which appears to be complete darkness to a common fowl. A horse can see better in the dark than we are able to do, and the cat and owl with their very large eyes are able to see sufficiently well to get about when there is very little light. However, no eye, no matter how large or perfect it may be, is of the least use in total darkness.

About a hundred years ago, the Abbé Spallanzani dis- 


\section{A New System for Preventing Collisions at Sea}

covered that certain kinds of bats had a veritable sixth sense; he noticed that the particular kind that possessed this remarkable sense was only provided with extremely small eyes that could be of little or no use to them in the dark-still they found their way about quite as well as cats and owls which have very large eyes. He then made experiments by blotting out the eyes of bats with red-hot irons and found that they got along just as well without eyes as with them. I quote the following from Cassell's Natural History:-

"He blinded these animals, sometimes by burning the eyes with a red-hot wire sometimes by removing the organs altogether, and even filling up the orbits with wax, and then allowed them to fly. In spite of the mutilation, the unfortunate little creatures continued quite lively, and flew about as well as those which still retained their eyes; they did not strike against the walls of the room, or the objects in it, avoided a stick held up before them, and showed a greater desire to keep out of the way of a cat or the hand of a man than to escape contact with inanimate objects. One of these blinded bats was set free in a long underground passage, which turned at right angles about its middle. It flew through the two branches of this passage, and turned without approaching the side walls. During its flight it detected a small cavity in the roof at a distance of eighteen inches, and immediately changed its course in order to conceal itself in this retreat. In a garden a sort of cage was prepared, with nets, and from its top sixteen strings were allowed to hang down. Two bats were introduced into this enclosure, one blinded, the other with its eyes perfect. Both flew about freely, never touching the strings with more than the tips of the wings. Finally, the blind bat discovered that the meshes of the enclosing net were large enough for it to get through, and made its escape; and after flying about for a time, made its way rapidly and directly to the only roof in the neighbourhood, in which it disappeared. In a room containing numerous branches of trees, or in which silk threads, stretched by small weights, were suspended from the ceiling, the bats, though blinded, avoided all these obstacles ; and when, after tiring themselves with their aerial evolu- 


\section{A Sixth Sense}

tions, they settled on some object for the sake of rest, they would immediately rise again on an attempt being made to seize them with the hand.

"From these experiments it was perfectly clear that in threading the galleries of caverns and other narrow and pitch-dark places to which bats commonly resort for their diurnal repose, these aninals were guided by some other sense than that of sight, and the worthy abbé set himself to ascertain what this sense might be. He commenced operations by covering the body of one of his blind bats with varnish, and found that this had no effect in rendering its movements uncertain. He then stopped up the ears with wax, and finally with melted sealing-wax, and still the bats obstinately persisted in avoiding obstacles placed in their way. Consequently they did not hear their way in the dark. There remained the senses of smell and taste. To test the former the nostrils were stuffed up, but the only effect of this operation was to bring the creature speedily to the ground, owing to difficulty of breathing. Little fragments of sponge impregnated with musk, camphor, or storax were fastened in front of the nostrils, and then the bats flew about as freely as ever, and showed the same power of avoiding contact with objects in their path. The removal of the tongue, as might be expected, produced no result."

During the last century several others have experimented with a view of ascertaining the manner in which bats are able to detect objects in their vicinity without the use of eyes. It was believed by many that they had an unknown organ which enabled them to find their way about in the darkest places without the use of either eyes or ears, and it was believed that this unknown organ was situated in the head.

"Cuvier, however, who was the first really to appreciate the results of these experiments, arrived at the conclusion, now generally accepted, that the wonderful power possessed by bats of directing their flight in places so dark as to render the sharpest eyes useless was due to an exceptional development of the sense of touch, residing especially in the great delicate membranous expanse of the wings. These organs are really of the 


\section{A New System for Preventing Collisions at Sea}

most delicate structure, and traversed by nerves, the fine ramifications of which terminate in little loops, like those found in those parts of the skin in man in which the sense of touch is manifested with the greatest perfection; and their surface is covered with rows of small thickened points, or papillæ, which may very probably have something to do with the perception of exceedingly delicate tactile impressions."

All of these experimenters are fully agreed that the bat does possess what might very properly be called a sixth sense, and that it is able to pursue and capture small insects in the dark under conditions in which eyes would be of little or no use. It is a very curious fact that, notwithstanding that the organ of the sixth sense is the most conspicuous organ possessed by the bat, none of our scientific men have discovered it. It was evidently too apparent to be observed, and reminds one of Christian in "Pilgrim's Progress" who was digging in the muck for a crown when the crown in question was directly over his head and very conspicuous. In many cases, the organ that gives the bat the sixth sense is spread all over its face. In the vampire bat the organ is on the tip of the nose; it stands up in the air, and is called the "shield," but in most of the small bats that catch insects on the wing, we find two little leaves, not unlike the wings of the insect that it pursues, standing up just in front of the ears. Others have the sensitive spots located on other parts of the face as will be seen by the following illustrations :- 


\section{A Sixth Sense}

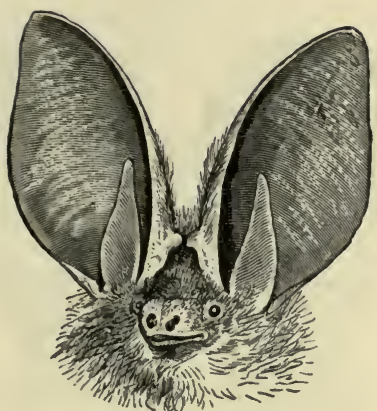

HEAD OF THE LONG-EARED BAT.

This bat has two wing-like leaves of great sensitiveness in front of the ears. These are very much like the wings of the insect which it pursues. The ears themselves are only able to hear rather high notes, but these two little leaves vibrate in unison with very low notes, much lower than the human ear is able to take in. It is therefore possible for this bat to pursue and capture insects in the dark without seeing them. The little leaves really endow the animal with a sixth sense.

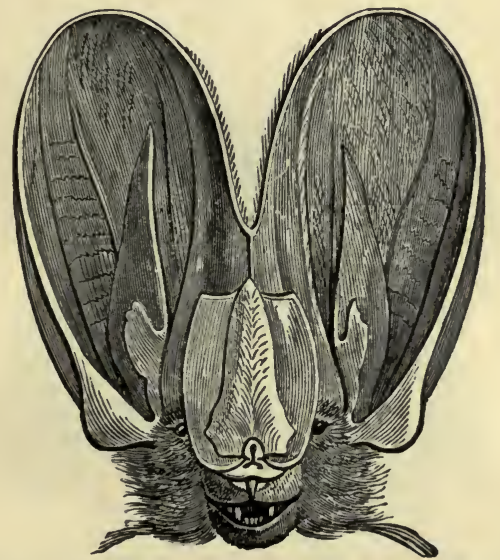

HEAD OF THE AFRICAN MAGADERM.

This bat has very large ears, and is also provided with a sensitive organ attached to the nose. It is a very fierce little beast-in fact, a species of a vampire, and feeds not only on insects, but it kills and devours other bats. 


\section{A New System for Preventing Collisions at Sea}

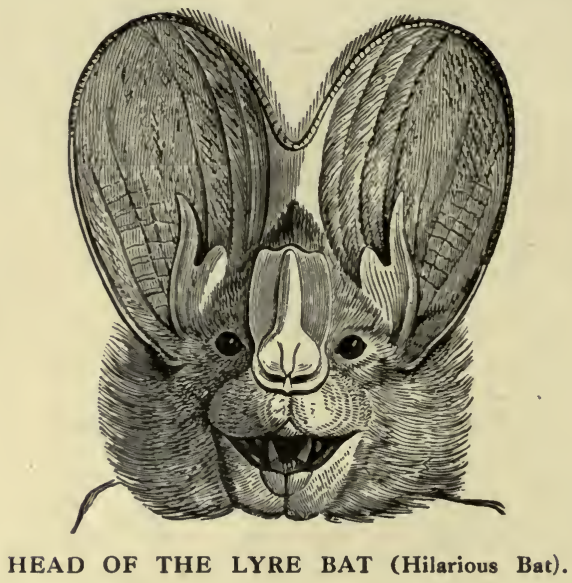

This bat has the sensitive membranes in the ears and also on the nose. It has fairly large eyes, and does not live altogether on insects.

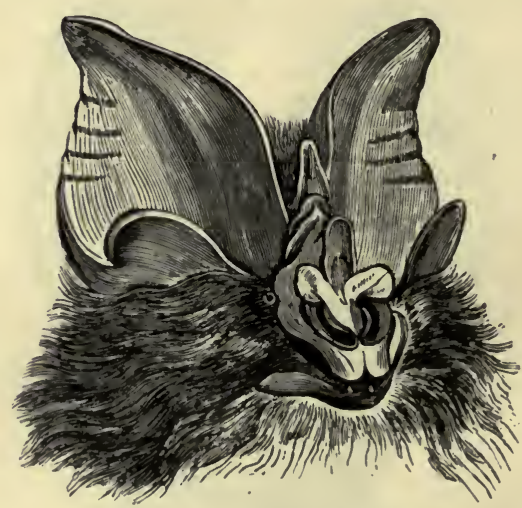

HEAD OF THE MOURNING HORSESHOE BAT.

This bat has a very complicated sensitive organ which occupies nearly the whole of the face. That it has very little use for its eyes is witnessed by the fact that they are extremely small. 


\section{A Sixth Sense}

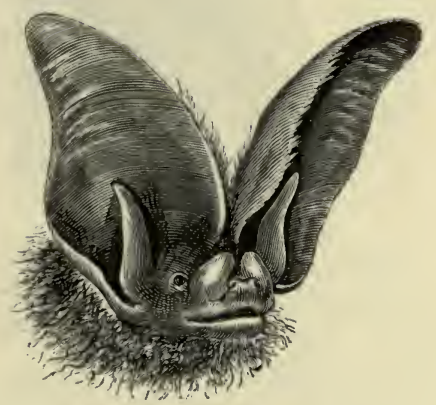

HEAD OF TOWNSEND'S BAT.

In this case the sensitive organ is in front of the ears and also in two eggshaped projections on the nose. The eyes are very small.

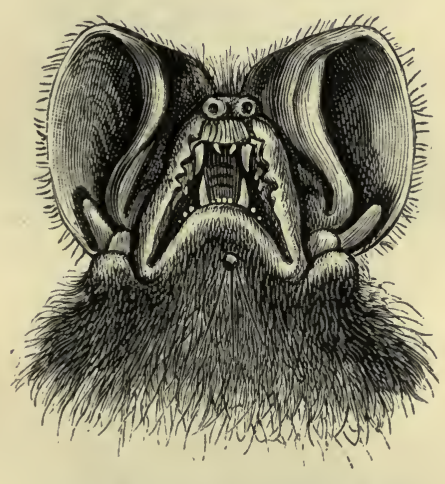

\section{HEAD OF CESTONI'S BAT.}

This bat has the sensitive organ in the ears and also on the upper lip. It is the kind that one finds in the dark passages of the pyramids of Egypt; it will be noted that its eyes are so extremely small that they do not appear in the engraving. 


\section{A New System for Preventing Collisions at Sea}

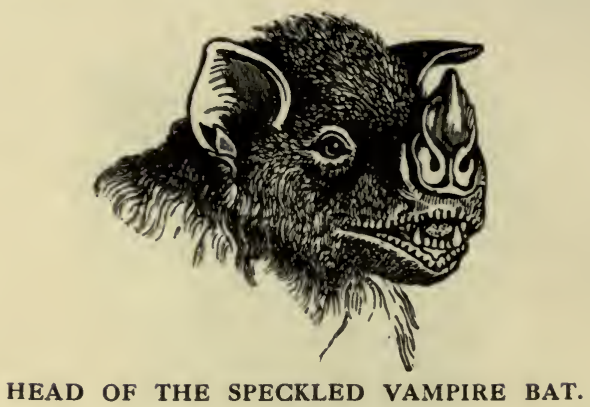

In this bat, the principal organ projects from the nose. It will, however, be noted that it has the rudiments of the wing-like leaf in its ear, which shows that its early ancestors belonged to the kind of bats that possess this leaf. This bat does not depend so much upon its sixth sense as many other kinds of bats, but it is provided with a fairly large pair of eyes.

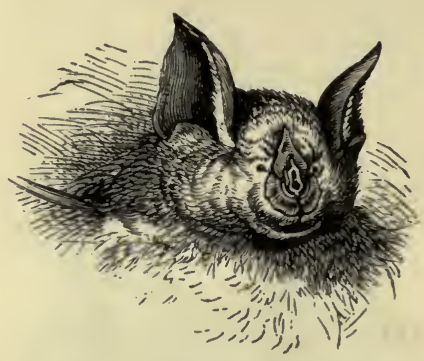

HEAD OF THE LESSER HORSESHOE BAT.

It will be observed that this bat has extremely small eyes, and that the sensitive membrane is attached to the nose and therefore cannot be considered a part of the ear.

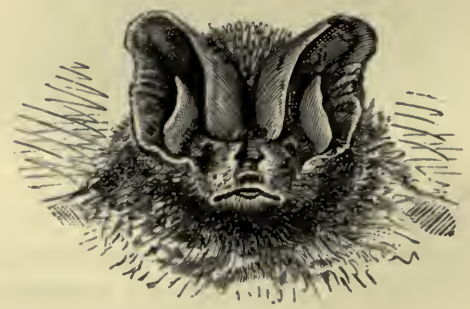

THE BARBASTELLE.

This bat is interesting from the fact that the organ of the sixth sense is located inside of the ears, but there is also a sensitive spot at the tip of the nose. 


\section{A Sixth Sense}

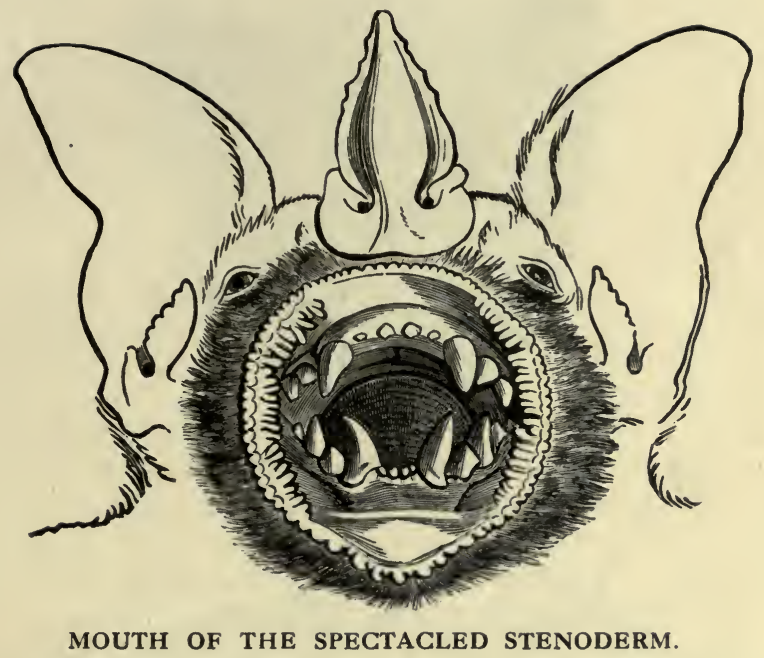

In this bat we find the sensitive organ not only in the ears and on the nose, but the lips themselves are sensitive. Tiis puiuiar arrangement enables it to seize its food in the dark and to know exactly what it is without seeing it.

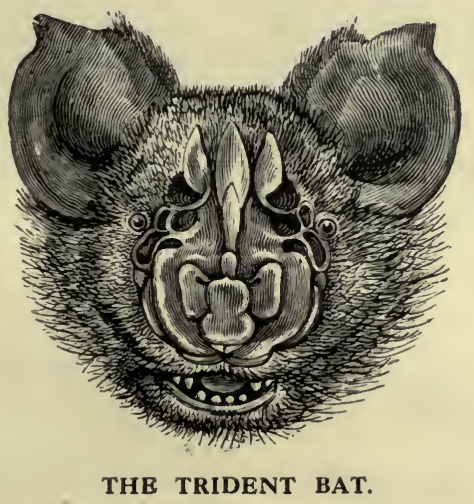

This species has a very complicated organ which covers nearly the whole of its face, and is extremely sensitive. In this species it certainly cannot be claimed that the sensitive organ of the sixth sense is a part of the ear. 


\section{A New System for Preventing Collisions at Sea}

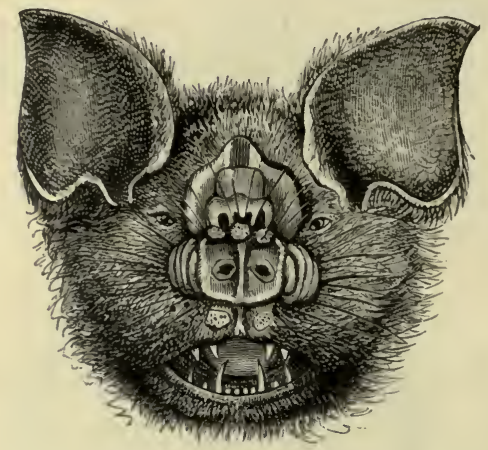

THE DIADEM BAT.

This'is a good example of the Leaf-nose Bat. Not only does it have the leaf attached to its nose, but it has a little sac which secretes a wax-like substance similarito ear-wax. Its eyes are extremely small, nevertheless it is able to get about in the dark quite as well as a bird would do in daylight.

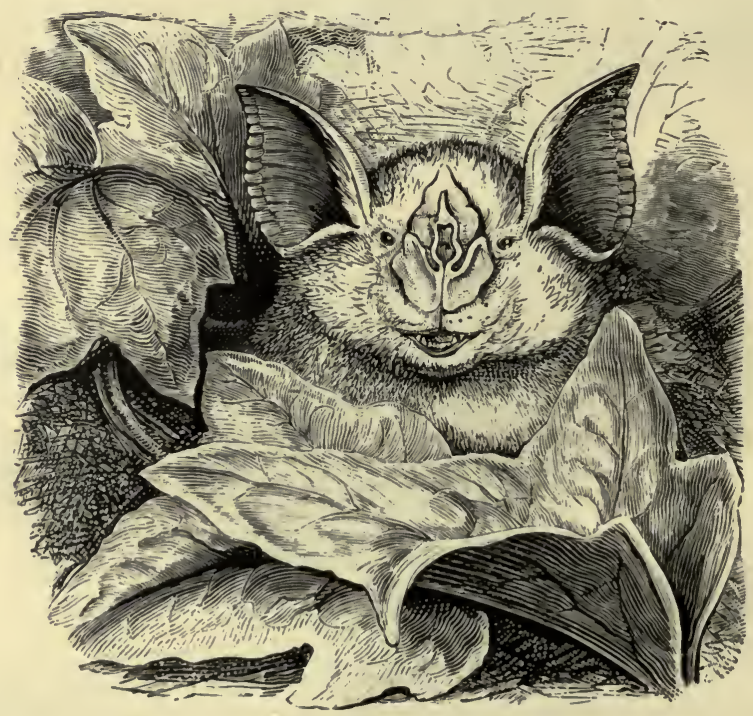

HEAD OF THE GREATER HORSESHOE BAT.

I It will be observed that the sensitive membrane is attached to the nose, and that the ears are not provided with the wing-like leaves. 


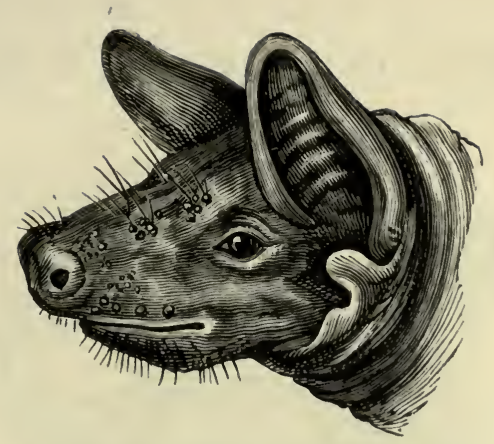

HEAD OF THE COLLARED BAT.

This bat is interesting in so far as it occupies a place intermediate between the bats that have six senses and those which have only five. The sensitive membrane is very small and projects from the neck; the face is provided with wart-like formations each of which is covered with sensitive hairs. The sixth sense is of very little use to this animal, but it is provided with fairly large eyes.

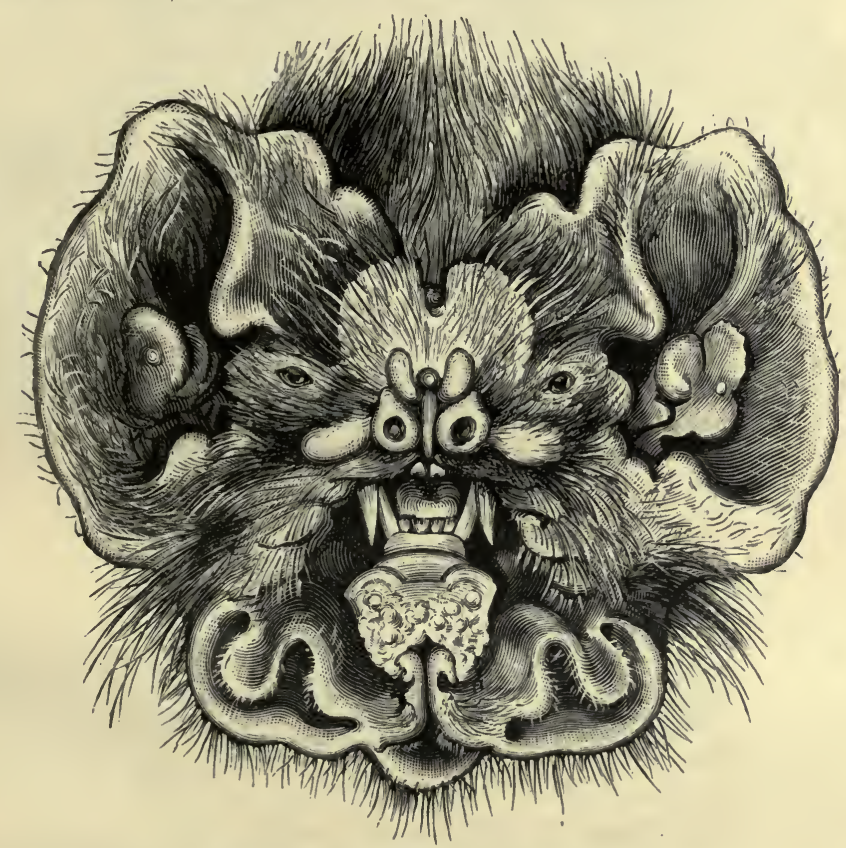

HEAD OF BLAINVILLE'S BAT.

In this bat, we have the highest development of the organ of the sixth sense to be found anywhere in animated nature. The whole tace, including the ears, is covered with this organ; the nose, ears and chin, are all occupied and covered with sensitive hairs. The eyes are small and of very little use. 


\section{A New System for Preventing Collisions at Sea}

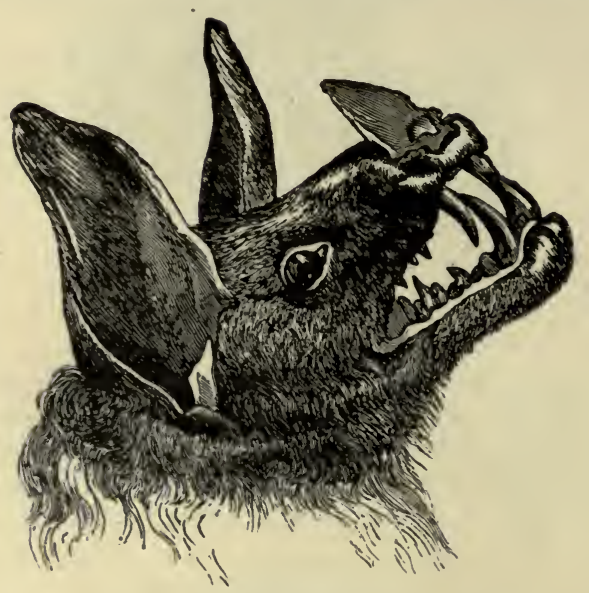

HEAD OF THE TRUE VAMPIRE BAT.

This bat does not pursue insects in the air and does not fly about in total darkness; the sensitive organs, both on the nose and in the ear, are in a rudimentary form and probably are of very little use, but the eyes are large, which show that it depends upon the sense of sight instead of the sixth sense.

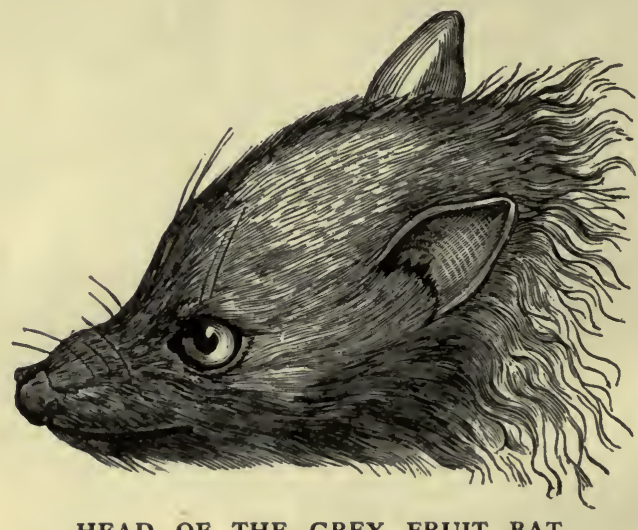

HEAD OF THE GREY FRUIT BAT.

This bat does not inhabit cavẹs or dark places, does not fly about on dark nights, and lives exclusively on fruit. It depends altogether upon its large eyes and moderate-sized ears, the organ of the sixth sense being completely absent. All bats with a highly developed sixth sense are provided with extremely small eyes, and $n$ o bat with large eyes has a highly developed sixth sense. 


\section{A Sixth Sense}

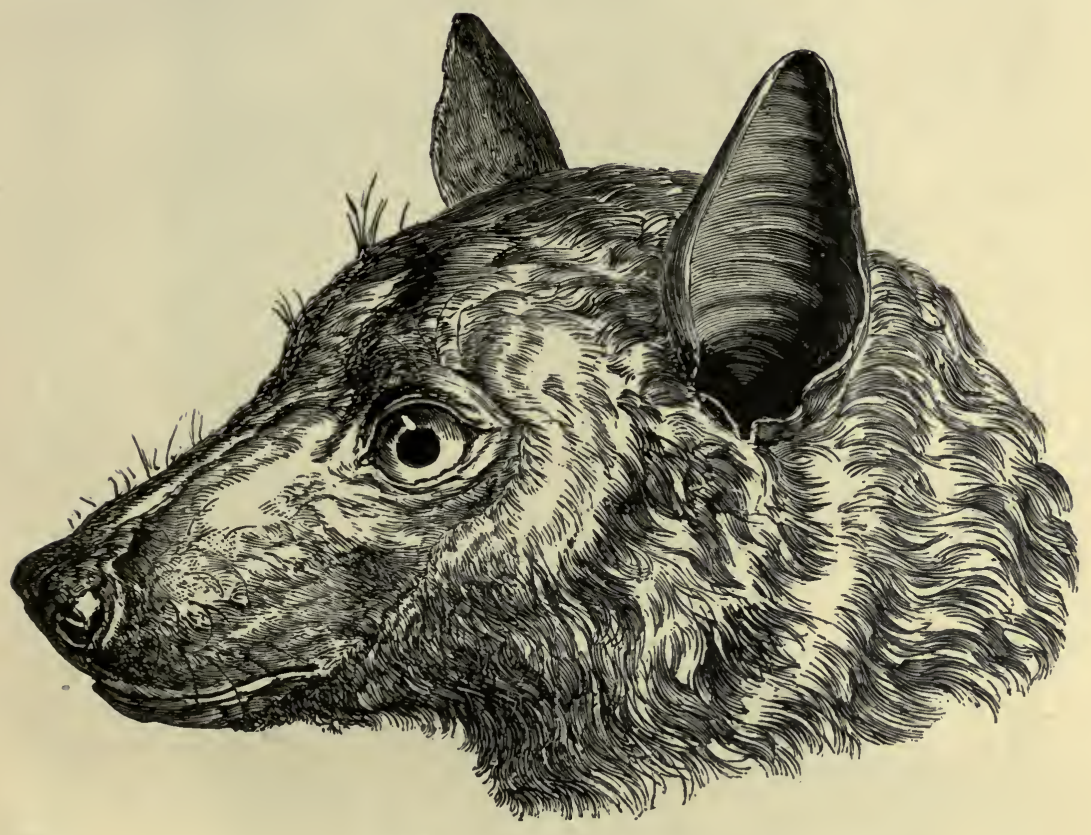

HEAD OF THE KALONG.

This is a very large bat; the body is about fourteen inches long and the wings have a spread of four feet or more. It does not inhabit caves, but makes its home among the thick foliage of trees. It feeds exclusively on fruit, has very large eyes, and not the least trace of the organs of the sixth sense. It should be noted that all bats endowed with the sixth sense are very small, and consequently move their wings very rapidly, while the large bats with slowly moving wings never have the sixth sense, and always have large eyes. 


\section{A New System for Preventing Collisions at Sea}

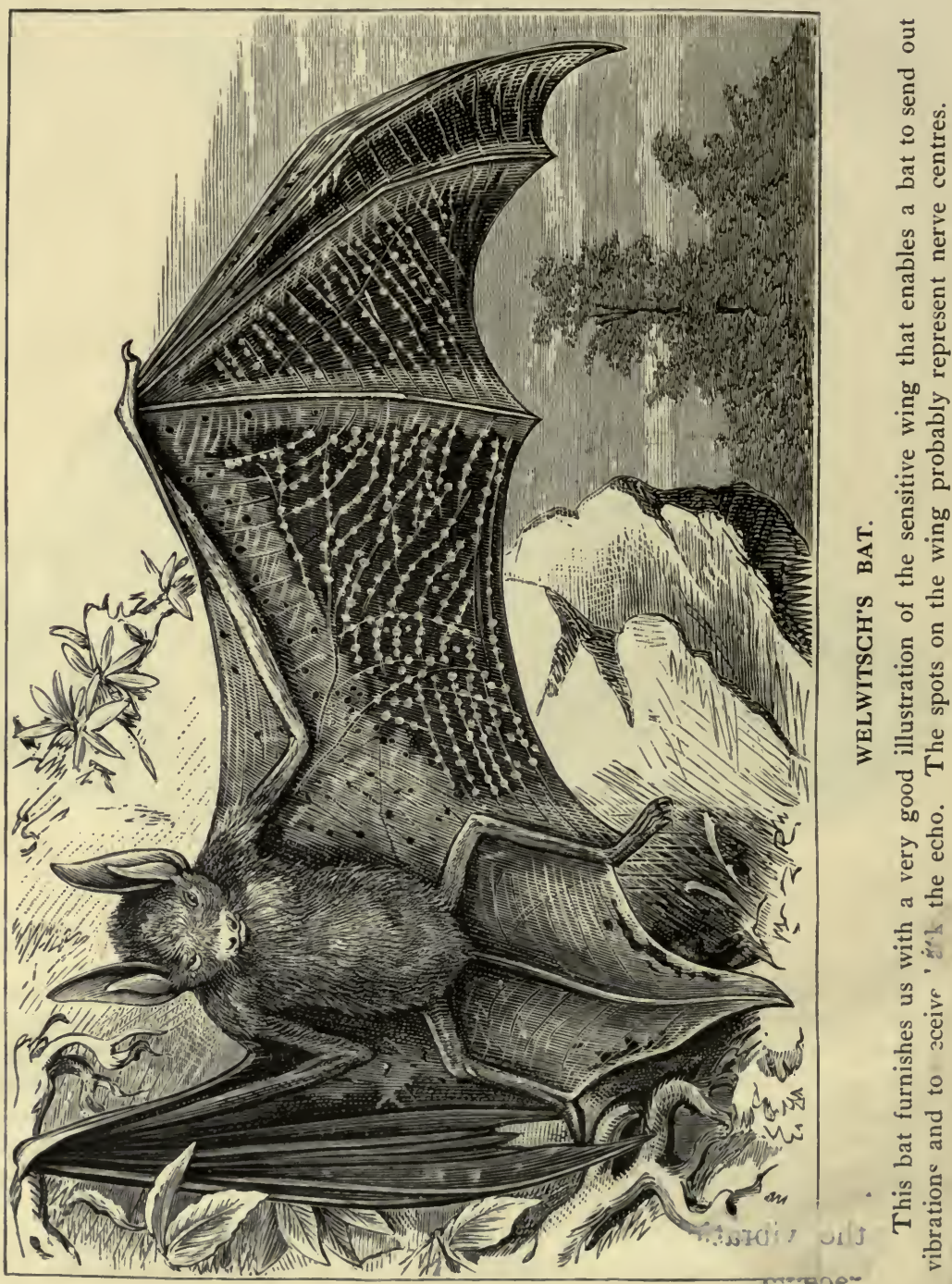




\section{A Sixth Sense}

Let us see now what takes place, and what it is that enables the bat to fly about through all manner of obstructions without touching anything, after the manner of a swallow. What enables it to pursue a fly or a beetle in a degree of darkness which renders eyes useless?

In the bats that feed on swiftly flying insects, we find that this small organ is about the shape and size of the wing of the insect on which it feeds. The beat of the insect's wings is communicated to this organ and enables the bat to follow the insect and seize it without seeing it. This is very simple and easily understood, because the insect itself produces certain atmospheric vibrations to which the little leaves in front of the bat's ear respond, but, when we come to inanimate things that give off no vibrations of themselves, how does the bat know of their presence? How is it able to judge of their character?

It has already been shown that the wings of the bat are extremely sensitive and very well provided with nerves, and the same is true of the various, organs on the face; of course, all of these are intimately connected with each other, and Ilso with the brain of the bat. TWhen a bat flies about in total darkness, the beat of its wings sends out a series of pulsations or waves after the manner of sound waves, but of too low a frequency to be considered as sound. These waves strike against all surrounding objects, and, like sound or light, are reflected back to their source of origin. The wings send out wuns or impulses and they are reflected back and cuuved by the sensitive organs which form a part of the face of the bat. (The extremely delicate nature of the bat's wings, together with the sensitiveness of its organ of the 


\section{A New System for Preventing Collisions at Sea}

sixth sense, enables it to judge the distance to any object by the lapse of time between the sending out and the receiving of the waves, because it takes some time, some fractional part of a second, for a wave to travel from the bat's wings to the object and return to the bat's face.

We know that this is the mechanism that gives to the bat what is practically a sixth sense. We know it must be true because it cannot be otherwise. That the bat possesses this power is completely beyond dispute, and this is the only way that it can be accomplished. But all bats do not possess this organ; the fruit-eating bats that do not fly about in total darkness have large eyes and never possess this organ, although in some cases, we find the rudimentary remains of the organ which they have inherited from their early ancestors, the same as we have inherited the Darwin tip.

Anyone who has made a study of heat, light and sound, and is familiar with the experiments of Professor Tyndall, must be struck with the similarity of the laws that govern these three. forms of energy. If the atmosphere is very clear, the searchlight will reveal objects at a considerable distance. In this case, let us see what takes place. The carbons in the lamp become intensely heated and send off certain very rapid waves in the ether: These travel with a marvellous rapidity, strike the object, become modified to some extent, and a portion of them returns and enables us to distinguish the object. It will, therefore, be seen that it is the waves that we send out that return to us. If we go into a dark room with a candle, these same ether waves are sent out in all directions; everything in the room becomes:illuminated, and the waves that return to our eyes enable us to know exactly what the room contains. 


\section{A Sixth Sense}

Every little detail is revealed with the greatest degree of nicety. In like manner the bat, on going into a perfectly dark cave where there is not the least suspicion of light, produces certain kinds of vibrations with its wings; these vibrations or waves are sent out exactly the same as the ether waves sent out by the candle. Everything in the cave is struck by these waves, and everything that is struck reflects back to the bat a portion of the waves that it receives exactly as is the case with the light. In this manner, the bat is able to move about with perfect ease exactly as a bird would do if the cave were brilliantly illuminated. Of course, this system of detecting objects, and of judging of their character and size, although sufficient to answer the purpose of the bat perfectly, cannot be compared at all with the waves that are sent out by a candle and received by our eyes.

It is very evident from the foregoing that bats which are able to fly about in total darkness, very much as birds do in daylight, do not depend upon their eyes or their ears, but have some other means of detecting the presence and locality, also the character, of objects-that is, they have a sense which is neither hearing nor seeing, and the organ of this sense is situated on the face of the bat. The extraordinary formation on the face of Blainville's Bat enables this animal to fly about in absolute darkness, avoiding all possible obstructions which may be placed in its path. These evolutions could not be performed without the aid of a sixth sense. I do not think it will be disputed that these animals do have a sixth sense.

Some small insects, such as mosquitoes, bees, and certain kinds of flies, produce a musical note with their wings; the 


\section{A New System for Preventing Collisions at Sea}

humming bird also moves its wings with sufficient rapidity to produce an audible musical note. In many kinds of beetles, the wings are not moved rapidly enough to produce an audible note, but every insect or bird that flies does produce atmospheric vibrations which are identical with sound and are governed by the same laws, the only difference being that the formation of our ears is such that they are unable to respond to such very low notes. This, however, does not prove their non-existence; it shows rather the limitation of our ears. It requires sixteen pulsations or vibrations of the air in a second of time to produce the deepest bass note that we are able to hear and which corresponds to the note given off by a 32 -foot organ pipe.

As a rule, the bats that are provided with the sixth sense are very small, and it is probable that they only make about ten to twelve strokes with their wings in a second of time. This, of course, produces an extremely low note that does not appeal to our ears, but it travels after the manner of sound-or light, for that matter-strikes all of the surrounding objects, becomes modified by their character and size, and is reflected back, and these reflections or echoes are received by the organ of the sixth sense and analysed, exactly the same as light waves would be by our eyes under similar conditions. It is, therefore, certain that the bat obtains its knowledge of surrounding objects by sending out certain atmospheric vibrations and receiving back in a fraction of a second later, the reflected and modified vibrations.

This is a purely mechanical problem. From the foregoing, I think its action will be understood, and I do not think it will be denied that we can imitate it to some extent mechanically. 


\section{A Sixth Sense}

The energy employed by the bat is certainly not more than one-thousandth part of a horse-power, but it serves the bat's purpose perfectly well.

Suppose, now, that we construct an apparatus that will produce atmospheric vibrations of about the same frequency as those produced by the bat, but instead of using the infinitesimal amount of energy employed by the bat, we use two or three hundred horse-power-that is, we send out waves that have an amplitude and energy at least three hundred thousand times as great as those sent out by the bat. These vibrations, although of great energy, will not be audible to our ears, but they will shake up and agitate light objects for a considerable distance, and will travel at least twenty miles, so that they could be received and recorded by a suitable apparatus at that distance, and would be able to travel at least five miles and send back to the ship a reflected echo that would be strong enough to be detected.

The quantity of steam required would not be very great, because the valve would not be opened very often, and when open would not remain open more than a second at a time; therefore, the total amount of steam required while signalling was actually going on would certainly not exceed ten horse-power.

The apparatus could also be used for communicating with other ships by giving off long and short blasts representing the dots and dashes of the Morse system. 


\section{THE APPLICATION OF THE SIXTH SENSE TO SHIPS}

HAVING ascertained that the bat does possess a sixth sense, and having discovered the organ that makes this sense possible, let us see now if we cannot accomplish the same thing in a rough sort of a way on a large scale for use on steamships at sea.

The human ear has a range between the note that is given off by a $\frac{5}{8}$-inch organ pipe and by one 32 feet long, but the sound given off by a $\frac{1}{2}$-inch organ pipe is not audible to us because the sound waves are too frequent; there is nothing in our ears that is able to respond to them, whereas the note given off by a 33 -foot organ pipe has not a sufficient number of vibrations in a second to bring it within the range of our ears. Low notes travel much farther than high notes. The American bull-frog, which is about the size of a man's fist, emits a deep bass note which can easily be heard at a distance of two miles-some writers say three miles.

It is known that whales are able to communicate with each other over vast distances by some species of low bellowing, but the note given off is too low to have any effect on the human ear.

At the age of thirteen, I discovered that the common mouse is quite unable to hear the voice of a man, but it is able to hear the voice of a woman, in which the number of vibrations per second is about four times as great as in a man's voice. 


\section{The Application of the Sixth Sense to Ships}

About one-half of mankind is able to hear the high note given off by crickets, and the same is true of the voice of bats. Extremely high notes have very little power; they do not travel far enough to be of any use at sea.

In providing a ship with a sixth sense, we have to consider three distinct devices: one for producing and sending out the necessary waves, one for receiving the reflected waves and making them audible by ringing bells, and another apparatus for recording the amplitude of the waves.

For producing the vibrations of waves, I prefer to use a modified form of a siren, the disc being rotated at a suitable speed by a motor of some kind, preferably an electric motor. I prefer to use a very high pressure of steam, to have all the parts large and strong, and to produce about fourteen or fifteen vibrations per second. These will not come within the range of the human ear, consequently they cannot be considered as sound, and as they are of great amplitude and power they are able to travel over great distances, and when they come in contact with a body, the waves are reflected back to the ship in the same manner.that sound would be reflected back, but this echo would not be audible to the human ear. I, therefore, provide an apparatus which might be considered as an artificial ear. It is provided with a large diaphragm tightly drawn over a drum-shaped cylinder, and so arranged that the atmospheric pressure is always the same on both sides, quite irrespective of any air blast. It is, therefore, always able to vibrate freely in response to the waves of the echo, and its vibrations are made to open and close certain electrical circuits which ring a series of bells of various sizes. If, for example, the object is very small 


\section{A New System for Preventing Collisions at Sea}

or at a very great distance from the ship, a very small bell rings, while a large object at a distance of two miles would ring a larger bell, and a very large object a still larger bell. This apparatus gives an audible notice if anything is ahead of the ship.

The other apparatus is similar, but instead of ringing a bell it produces a diagram of the disturbances in the air-that is, when there is no noise except that due to the action of the ship or the seawaves, a wavy line is produced, but whenever the vibrations sent out by the vibrator strike an object and return, the wavy line on the paper becomes very much increased in amplitude so as to be easily observed (see frontispiece), and the distance that the object is from the ship can be measured by the length of the paper strip between the giving off of the vibrations and the receiving of the echo; therefore, the distance can be determined with a considerable degree of nicety, and the size of the object may be determined by the amplitude of the waves that return.

Very extensive experiments were conducted about forty years ago by Professor Tyndall at the South Foreland. He found that a deep note emitted by a powerful siren travelled a very long distance, and he was rather surprised at the volume of sound that was reflected back from a ship. At that time it was generally supposed that snow, rain, and fog were very unfavourable to the travel of sound, but in his experiments he found that such was not the case. I quote the following from his work on "Sound":-

"Rain has no sensible power to obstruct Sound.

"Hail has no sensible power to obstruct Sound.

"Snow has no sensible power to obstruct Sound.

"Fog has no sensible power to obstruct Sound." 


\section{The Application of the Sixth Sense to Ships}

"The air associated with fog is, as a general rule, highly homogeneous and favourable to the transmission of sound. The notions hitherto entertained regarding the action of fog are untenable."

The most unfavourable weather for sound is when the sun is shining brightly and when the air is optically perfectly clear. Under these conditions, we have heated air rising up from the earth, and cooler air descending; this produces a kind of a glimmer in which it is very difficult to sight a gun at long range with any degree of exactness, but my apparatus would not be needed in this kind of weather.

It is well known that the air around a large iceberg is extremely cold-in fact, so cold that certain scientific men have thought that it might be possible to detect the presence of icebergs by the use of a delicate thermometer; but the cold air does not extend far enough around the iceberg to make this practical. Cold air, however, lends itself admirably to the use of my apparatus, because the air itself about the iceberg, being of a different density from the surrounding air, acts as a reflector returning the vibrations to the ship.

In Professor Tyndall's experiments I find the following :-

"In the experiments at the South Foreland, not only was it proved that the acoustic clouds stopped the sound, but that the sounds which had been refused transmission were sent back by reflection." 


\section{SOME REMARKS ON THE OPERATION AND USE OF THE APPARATUS}

THE apparatus for producing the atmospheric vibrations should be placed well forward on the main deck or in any other position where it can be turned about from port to starboard. It should be very firmly secured to the deck, and connected with a high-pressure boiler by a three-inch pipe. A straightway valve should be placed in the pipe near the boiler, and means should be taken to prevent accumulation of water in the pipe leading to the apparatus.

Of course, there would be no use for the apparatus except in dark, foggy or stormy weather, unless it was to be used for communicating with other ships. When, however, the presence of other ships or icebergs is suspected at night, the apparatus should be used constantly, sending out the blasts in every direction. If the sea were perfectly clear, the blasts sent out would be recorded at the very instant of their production, but no echo would be returned other than that due to the waves of the sea, which would produce a zigzag line of small amplitude; but if there should happen to be an object of any considerable size at a distance no greater than two or three miles, the zigzag line on the paper would be changed, the amplitude of the waves would be greater and would be very noticeable. To make sure, the blasts could be repeated several times; and then, if the result should be always the same, it would indicate the presence of some object, and the 


\section{The Operation and Use of the Apparatus}

length of paper between the primary blast and the echo would indicate the distance that the object was from the ship. It might be so arranged that one inch of paper represented a mile.

The receiving instruments can be placed anywhere on the ship where they can be turned in the same direction that the siren is turned, and there may be as many of them as desirable.

Of course, there are vastly more accidents caused by running ashore than by collisions at sea, and it does not require a very bold sea front to produce a very strong echo. For example, in approaching the coast of Ireland, the echo would be sufficiently strong to show itself over a distance of at least ten miles.

To many it will doubtless appear very difficult, even on the verge of the impossible, to reveal the presence of objects at sea by simply sending out atmospheric vibrations and receiving the echo of the same. One might ask, how can it be possible to judge of the size, distance, and character of the object by the echo? If, however, we make a careful study of the matter, we shall find, if we send out a powerful blast of sound like a deep musical note, that it will travel a long distance, and if it strikes any object of considerable size, it will send back a reflection or echo. Sound is nothing more nor less than atmospheric vibrations. If there are less than sixteen vibrations in a second of time, they are not audible to our ears; we do not hear them, although we may feel them. They may be of great power and able to travel a long distance, and if they should happen to strike any object they send back an echo which, although completely inaudible to our ears, is sufficient to record itself by suitable 


\section{A New System for Preventing Collisions at Sea}

apparatus, and the record thus made will give us a fair idea of the object struck. It will indicate its size and shape with a fair degree of accuracy; it will indicate its direction from the ship, and will also show its distance with great accuracy. It will distinguish a ship from an iceberg, will show whether the object is stationary or moving, and if moving the direction and velocity of such movement.

Before describing fully the modus operandi of this apparatus, we will first examine some of the phenomena relating to sound and the accompanying echo.

On one occasion I witnessed a stroke of lightning at a distance of ten feet. It was simply a blinding flash and a short, sharp, ear-piercing snap; I did not hear any thunder. The duration of a flash of lightning is only a small fraction of one-thousandth part of a second, and still we hear the thunder roll for some seconds, perhaps ten or more. All the noise is produced in less than one-thousandth part of a second. The thunder is not the direct sound, but the echo, which varies greatly, according to the character and distance of the object that reflects the primary sound. On one occasion, while on the very roughest part of the Tête Noire, we were overtaken by a very violent and noisy thunderstorm. There were many large objects all around us, and each flash of lightning was followed by noises coming from all directions and resembling musketry fire. The clatter was so great that I failed to hear a "thunder roll" of the kind so well known in all level countries and at sea. The rolling and reverberating sound known as thunder that follows a lightning flash is all made up of echoes. The first short sharp primary snap sends out vibrations that strike the clouds; if the clouds were solid and 


\section{The Operation and Use of the Apparatus}

hard the echo would also be sharp and short, but as the clouds only vary slightly in density from the surrounding air, the sound is much modified and softened-that is, partaking in no small degree of the nature of the reflecting body. Clouds are of all densities and are at various distances. The primary vibrations produced by the lightning are echoed and re-echoed between the clouds and the earth, producing a very complicated series of sounds of widely varying degrees of intensity. Thunder is a reflection that reveals the character of the object in our vicinity. Would not a blind man with good ears and a knowledge of the laws of sound as relates to thunder be able to judge something of the nature of his surroundings by the character of the thunder? In the system of Zadig described by Voltaire, we find what a lot of information one is able to obtain from very slender data. The same idea is elaborated by Sir Conan Doyle in his "Sherlock Holmes." In my apparatus, we have to examine certain little zigzag lines on a strip of paper; the relative size of the zigzags, their position on the paper, and their number, can be read and understood without the use of anything approaching the skill of Zadig or Sherlock Holmes. In order to bring this subject within the grasp of all, let us suppose a case.

We will imagine that all ships of any considerable size crossing the Atlantic are provided with my apparatus. We embark on one of these ships at New York at 4 o'clock in the afternoon, and a few hours later we are well out on the Atlantic in a moderate sea way, and adjust our receiver so that the small bell sounds about every ten seconds, due to the noise of the wind and waves. We try our recording instrument, and find that it only produces a wavy line, quite 


\section{A New System for Preventing Collisions at Sea}

uniform. We next send out a powerful blast, and find that this has produced a decided series of zigzag lines on the strip of paper. The bells have not sounded because the electric current that rings them is cut off by the act of opening the steam valve of the siren. Nothing is on the paper except the marks produced by the primary blast and the sea waves. We repeat our experiment by pointing our instruments a few degrees to both port and starboard; still no result. Therefore there is evidently no large object ahead of us, and we proceed in the darkness at "full speed, repeating our experiments every ten minutes if the weather is foggy. At about midnight, we find a very faint indication of an echo; the wavy line due to the sea is slightly modified when our instruments are pointed ten degrees to the port, but not when pointed dead ahead or to the starboard. We repeat at the port side with the same result as before, but we find that the little bell of the indicator shows an increased ringing, and a few seconds after we send out our blast from the siren, or vibrator, as we should call it. The echo reaches us 20 seconds after sending out the blast; consequently, it took ro seconds for our vibrations to reach the object and another ro seconds for the reflected vibrations to return; therefore, the distance is slightly over two miles. Our ship is doing 20 miles per hour, and one minute later we send out another blast, but the result is no stronger than before, so we change the direction of the blast and find that the greatest effect is produced when the blast is sent dead ahead, also that the distance between the object and our ship is being reduced at the rate of 35 miles per hour; therefore the unknown object is evidently a ship making 15 


\section{The Operation and Use of the Apparatus}

miles per hour, and travelling towards us slightly to our starboard. Our next blast shows us that the ship is only a mile distant, and very much to the starboard; we follow her direction, and when she is in a position to present her broadside to us we find in sending out a blast that the echo is very strong, the bells at the receiver ring violently, and the recorder makes a large and distinct marking on the paper strip. The weather has been so thick that we have not seen the ship, but we have a fair idea of her; we know her speed and the direction in which she is sailing.

The next day is fine and clear; we meet several ships and send out blasts and note the readings. Amongst these ships is a large fully rigged sailing ship with all sail on. When she is off our beam, we turn our indicator and recorder in her direction and send out a strong blast of two seconds' duration; this is followed in six seconds by a ringing of all our bells, and the recorder has a clear record showing that the object sending back the waves or vibrations is of great size and high out of the water.

We are now off the New England coast; night is coming on and there is a slight mist, so that a ship's lights cannot be seen more than half a mile distant. Suddenly the two smaller bells at our indicator ring violently; we have not sent out a blast, and so we know it is the blast from another ship's vibrator. We answer by a blast and then liberate the clockwork, so that the paper strip is fed out continuously, and very soon our recorder shows the letters A B C to be followed by a message and a reply. The ships are now 30 miles apart, and we find that the primary blast will work our recorder at that distance, or more than twice as far 


\section{A New System for Preventing Collisions at Sea}

as the echo; 45 minutes later we send out a blast and receive a faint echo which tells us that the ship is ten miles distant. A few minutes later the echo is very strong, makes a decided record, and rings our smallest bell. We make other records as the ship approaches, and when she is off our port beam, broadside on and only half a mile distant, she sends us a blast that we can feel if not hear. It rings all our bells violently, and causes every light object on the deck to vibrate.

The following day we only exchange messages with other ships; night comes on, we encounter a dense fog and by midnight are on the Banks of Newfoundland. We are constantly sending out blasts without receiving any response. However, at about two o'clock in the morning, we do receive a response ; it is only slight and only a short distance away, so we know it is some small object, which we soon pass without seeing it. Later on we receive a series of records from each blast, showing that there are several small objects in our vicinity, probably fishing boats. We are able to locate them and measure their distance, and if any of them are dead ahead of us, we change our direction so as to give them a wide berth. When daylight appears, we are still in a dense fog; we make out and communicate with several ships that have our apparatus, but we fail to see any of them. About nine o'clock in the morning we have a new experience; we send out a blast and receive back an echo showing that there is an exceptionally large object very nearly dead ahead of us. We know it is large because the distance indicated is ten miles and the record quite distinct. By sending out repeated blasts, we find that the distance between us and the object diminishes about one-third of a mile in a minute. This, of course, is due to our own speed, and indicates that the object 


\section{The Operation and Use of the Apparatus}

is stationary. When we are two miles apart, the reflection of our blasts rings the bells, and the indicator shows a different record to what we have seen before. The markings on the paper strip are of considerable size and commence sharp and abrupt, but the ending is not sharp or distinct. There is a tailing out of spots made by the zigzag lines. The total length of the echo is thus made longer than that produced by the primary blast. This shows that there is some kind of a cloud about the object of a different density from the surrounding air and that it is of considerable size. Therefore, we draw a logical conclusion. The object is of great size; it is stationary, and it has something about it that modifies the echo; consequently, the record on the paper strip resembles that obtained from both a large, solid object and a cloud. Therefore, it must be a large iceberg surrounded by cold air. We change our direction so as to pass it on our port side at a distance of half a mile. Fortunately we have barely passed when the fog lifts and discloses an enormous iceberg surrounded by smaller pieces of ice that have been broken off. The following day we pass many ships, and with our apparatus we inform them of the size and locality of the big iceberg. We are now well off the Banks, but still in a locality where icebergs may be found, and in the afternoon we come in sight of a group of these dangerous objects of all sizes. We give them a blast and the record produced is peculiar. Instead of one spot of zigzag lines on the paper strip, there are about half a dozen spots. Each iceberg within range has made its own record, indicated roughly its size and accurately its distance. Soon night is on us again, accompanied by a slight mist that obliterates 


\section{A New System for Preventing Collisions at Sea}

the lights of passing ships. At about nine o'clock, after sending out many blasts to port and starboard, and also dead ahead, we have a very slight indication that there is some large object ten miles distant, and very nearly in the direction we are going. We expect to get a stronger reading in a few minutes, but do not do so. However, we keep on sending out blasts, and at the end of an hour the readings are more distinct and the distance is reduced from ten miles to seven, showing that the object in question is evidently a ship going in the same direction as ourselves but at a lower speed. We come up to her and pass her in a short time; we next find that there is a very large object off our starboard beam. Our recorder shows the distance to be over twelve miles, and still the markings are quite distinct. What can it be? Reason tells us that it is a big liner with her immensely large broadside in a position to send back to us an echo such as we have never received before at such a distance. We continue sending out blasts, and soon find that the big ship is going in the same direction as ourselves, and at a speed of fully three miles an hour faster than our own ship is travelling. In a short time she is so far ahead of us that we cannot receive back an echo.

The day following is very fine and cloudless; the sun shines down from a deep blue sky with remarkable intensity. There is practically no wind. However, at about midday, the little wavelets on the surface of the water show that the air is in motion. Currents of cold air are descending, spreading out over the surface of the water, and producing the little waves that enable us to locate both the descending and ascending currents. The warm air produced by the intense heat of the 


\section{The Operation and Use of the Apparatus}

sun shining on the surface of the water is constantly rising and its place being taken by the colder air above. It is like the rush of the third-class passengers through the rushing first class at a railway station. This of course produces a great many conflicting currents of air of different densities, certainly very favourable for the production of acoustic clouds; optically the air is clear and transparent. At two o'clock we send out blasts in various directions, and, although there is nothing in sight, we receive responses of considerable power, showing unmistakably the presence of invisible acoustic clouds. The readings on the paper strip, however, are drawn out and much longer than the primary blast. Acoustic clouds never appear in foggy weather; they are produced by many conflicting currents of air, of different densities, the result of bright and unobstructed sunshine.

The last three days of our voyage are cloudy, rendering observation impossible. It is a very dark and foggy night, and we are approaching the rugged coast of Ireland. We work our vibrator constantly, sending out strong blasts every few seconds, but we receive no response until near morning. We know that there is no danger, as our apparatus shows that the coast is clear, so we keep on full speed until we receive some response to our blasts. The first is very feeble and comes from a distance; twenty minutes later the record is strong and distinct, and there is more than one record. Some objects are only three miles distant and of no great size, whilst others are indicated fully ten miles distant, and from the size and shape of the records must be of great size. It is the uneven coast of Ireland, with mountains in the background. The fog continues dense; still, with our apparatus we are able to skirt the coast, 


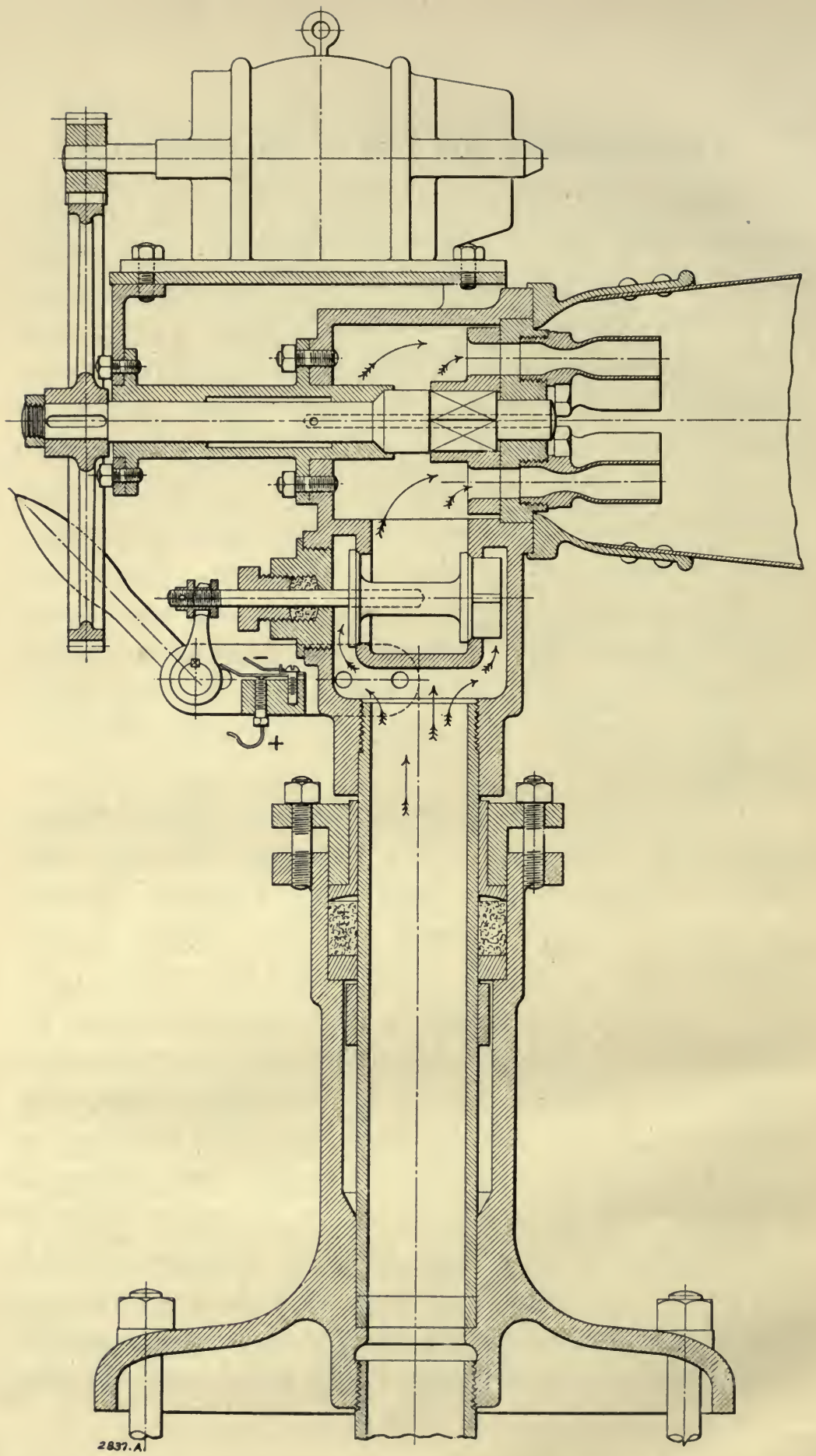

Plate 1.-Vertical Central Section of the Apparatus for Producing the Vibrations. 


\section{The Operation and Use of the Apparatus}

keeping our distance from the shore, and have no difficulty of feeling our way into port.

Plate No. I represents a vertical central section of the apparatus for producing the vibrations. The rotating disc is driven at a uniform speed by an electric motor, so that the pitch of the note sounded is always the same. The steam enters the central pivot, passes through the balanced valve, and escapes through

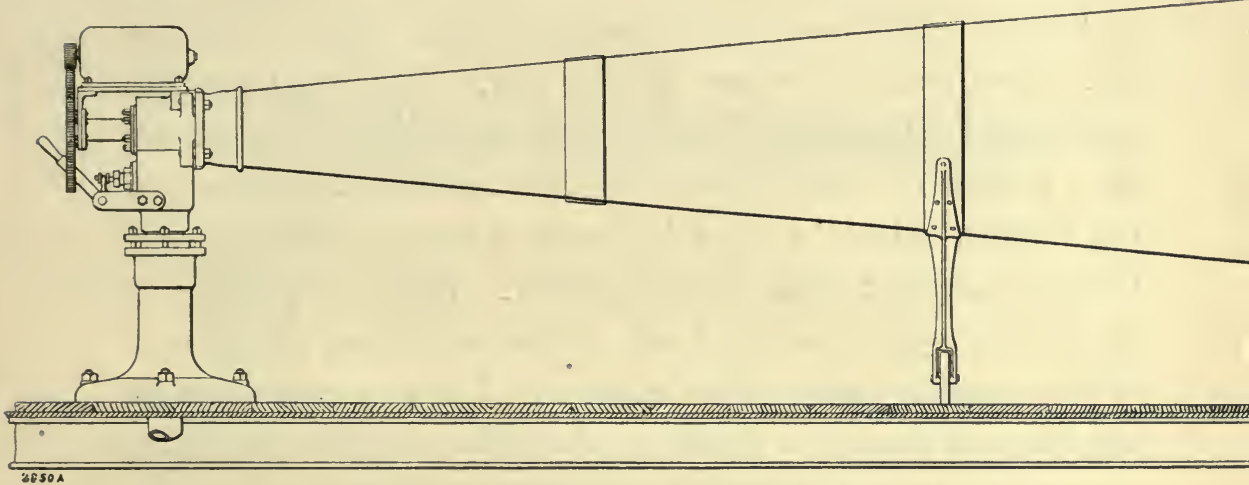

Plate 2.-Side Elevation of the Siren or Vibrator.

expanding nozzles into the small end of the trumpet. The balanced valve is opened and closed by means of a handle, as will be seen; the opening and closing of the valve also makes and breaks electric circuits.

Plate No. 2.-A side elevation of the complete apparatus on a greatly reduced scale. The trumpet, being of great size, is supported by a wheel. The trumpet may be turned in any direction without interfering with the supply of steam, which enters through the centre of the pivot on which the apparatus revolves. It is proposed to use this form for longdistance work, but where it is desirable to spread the vibra- 


\section{A New System for Preventing Collisions at Sea}

tions out and to occupy more territory, a much shorter trumpet is employed, which is bell-mouthed and does not require any support other than the central pivot.

Plate No. 3.-A vertical central section of the apparatus for converting the inaudible waves of the echo into sounds which are audible to the human ear. This apparatus is provided with a thin, tightly drawn diaphragm. The atmospheric vibrations cause this diaphragm to vibrate after the manner of the head of a drum, and in moving it opens and closes electrical circuits and causes bells of various sizes to ring. The circuit making and breaking apparatus is shown in the smaller illustration. Any degree of fine adjustment may be made by means of the spindle, which is provided with a screw thread passing through a support inside of the cylinder. Whatever pressure of air there may be on the front of the diaphragm produces a similar pressure inside of the cylinder. The air passes through the felt, and through a small opening that is adjustable in the connection through which the screw spindle passess.

In Plate No. 4 we have a vertical central section of the apparatus for recording the frequency and the amplitude of the atmospheric vibrations that strike the diaphragm. A very small and light rod is attached to the centre of the diaphragm which passes to the rear and carries a pencil point that records the vibrations on a strip of paper similar to that used in a Morse instrument. When the operator moves the handle of the siren downward, he not only opens the steam valve, but closes an electric circuit which releases the mechanism of the Morse instrument and allows about fourteen inches of the paper to be fed out, all of which is shown in the drawings.

The primary blast sent out by the siren is registered on the 

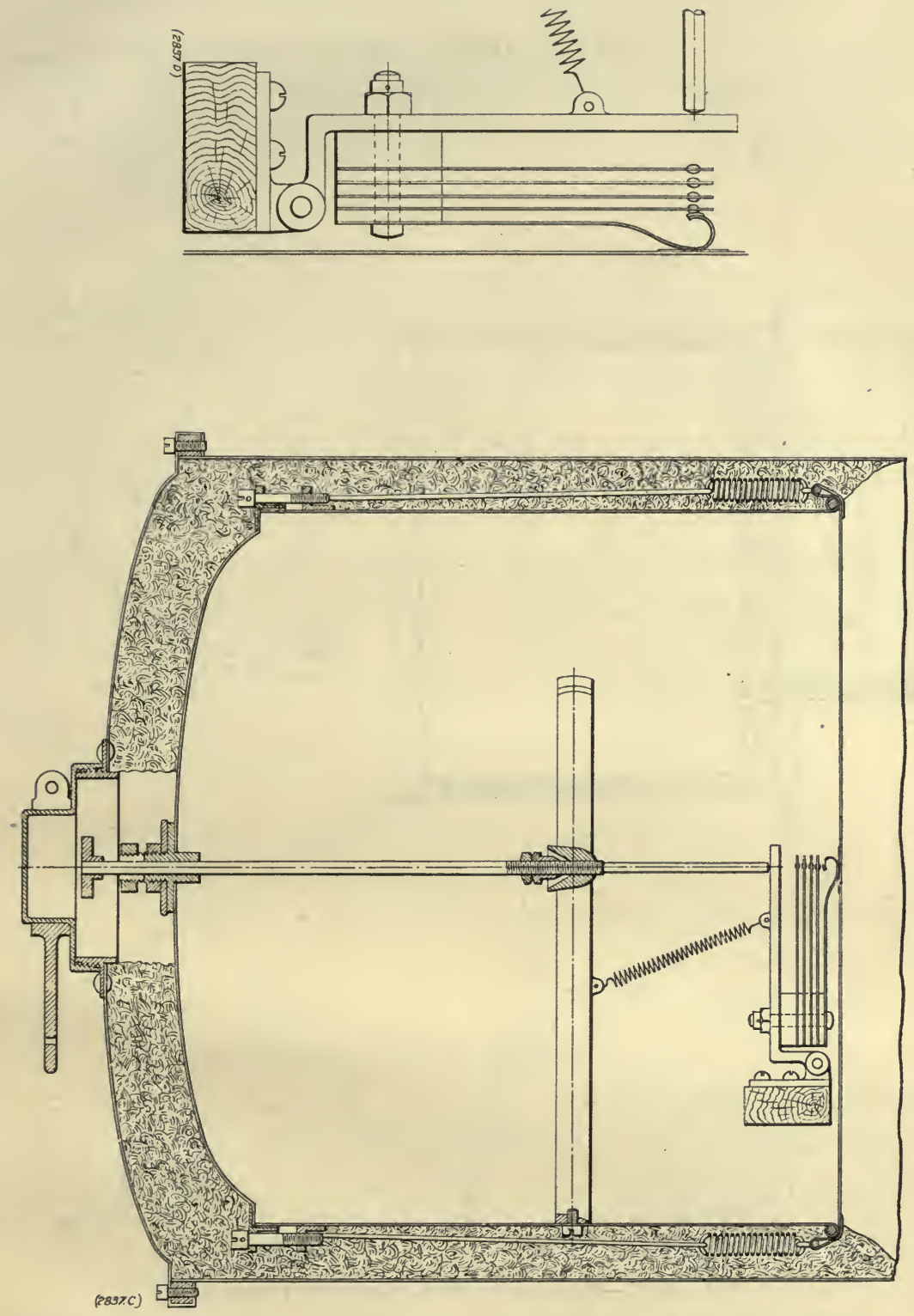

Plate 3.-Receiver that Makes and Breaks Electrical Circuits for Ringing Bells. 


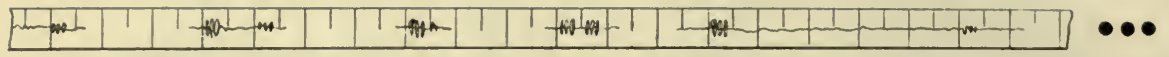

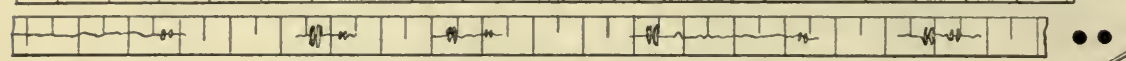

Thank -
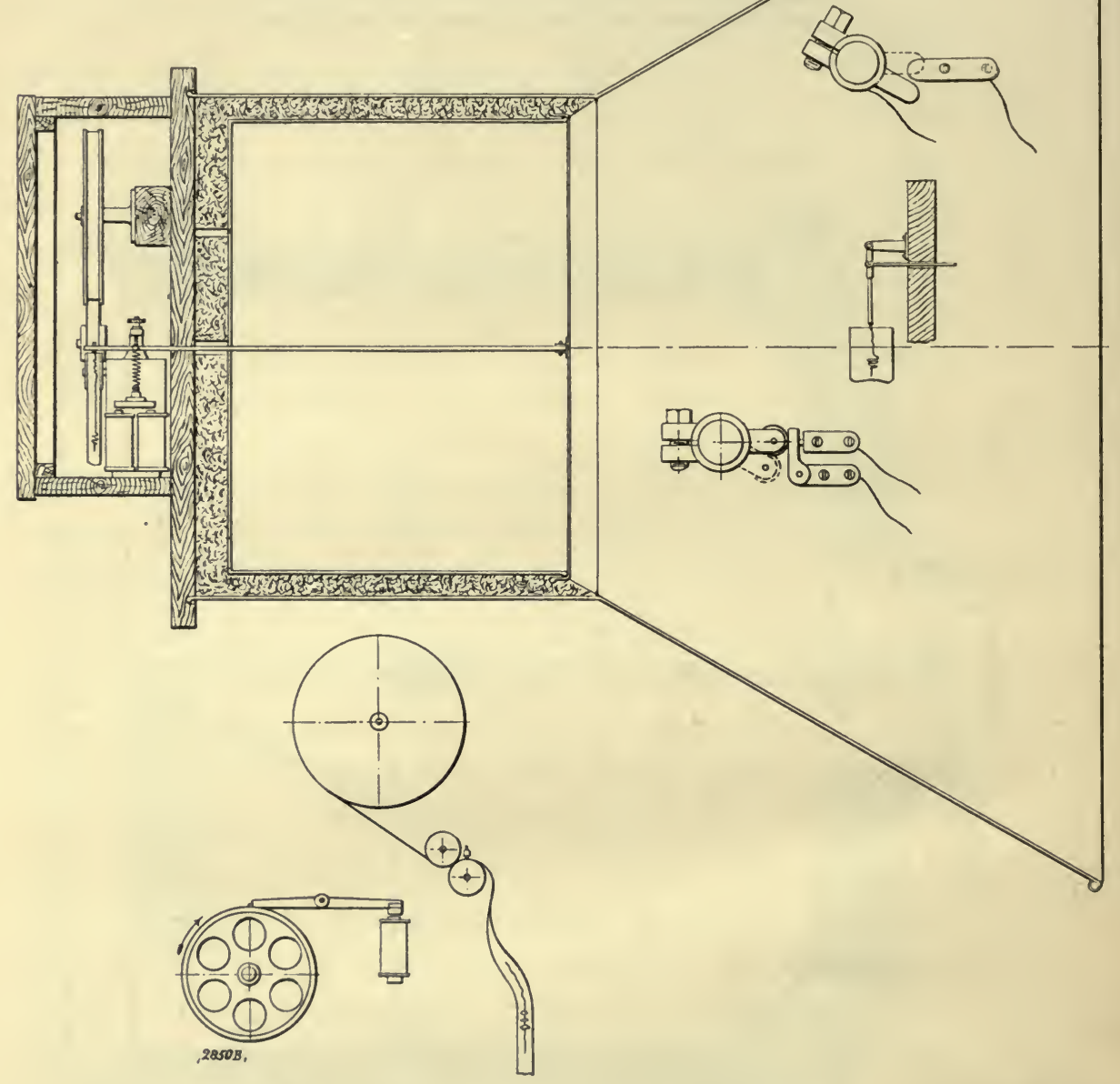

Plate 4.-Receiver for Recording the Vibrations. 


\section{The Operation and Use of the Apparatus}

paper strip, and the distance that the object is from the ship may be determined by the distance between the record of the primary blast and the echo received, as shown in the drawing.
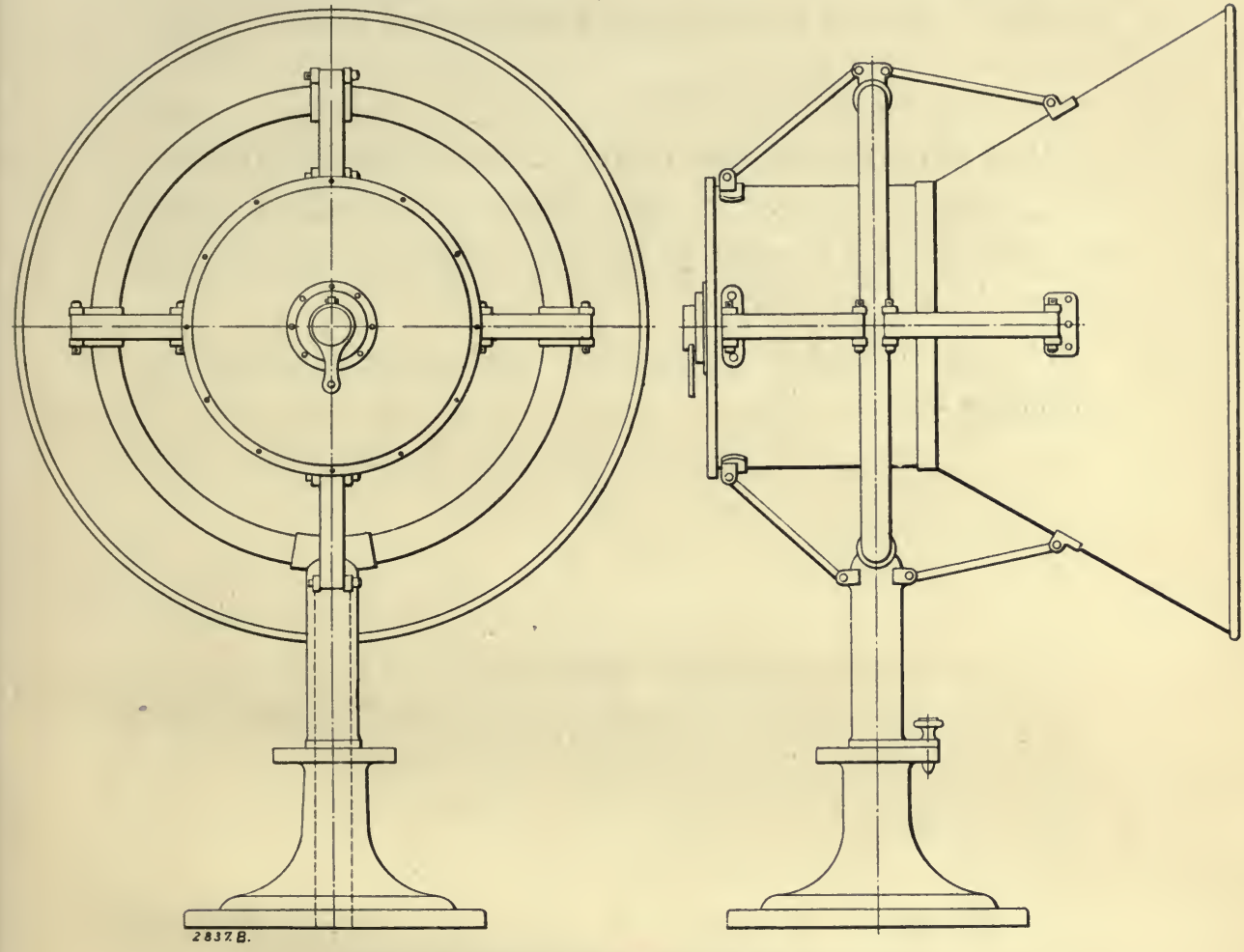

Plate 5. - System of Mounting the Receivers.

Observe the markings on the strips of paper shown at the top of the drawing.

Plate No. 5.-Some engineers might imagine that it would be very difficult to mount these delicate instruments on a vibrating ship so as not to interfere with their fine adjustment 


\section{A New System for Preventing Collisions at Sea}

and accurate working, but this trouble is overcome by mounting them as shown in Plate 5. They are placed inside of a large hoop and suspended by eight pure rubber straps. This effectually prevents them from participating in any of the vibrations that are peculiar to a high-powered ship.

At a mean temperature of $50^{\circ} \mathrm{F}$. sound travels $\mathrm{I}, \mathrm{I} 00$ feet in a second of time. It takes sound 4.8 seconds to travel one mile and 9.6 seconds to reach an object one mile distant and send back an echo.

The guns of H.M.S. Thunderer were recently heard at a distance of 100 miles. 


\section{ICEBERGS}

IN many cases, icebergs are of immense size, and they are always slowly melting. Many have supposed that it would be possible to detect their presence by a change in the temperature of the water, but nothing could be farther from the truth.

At the spot where the Titanic went down the water is over two miles in depth. Water, being a non-conductor of heat, can only be cooled or heated by convection-that is, in order to be cooled it must touch something that is cold. About eight-ninths of the bulk of an iceberg is below the surface of the water, and only one-ninth above. As the sea water comes in contact with the ice, a certain portion of the ice is dissolved, and each pound of it that is dissolved absorbs heat enough from the surrounding sea water to raise one pound of water $140^{\circ}$-that is, it requires 140 British thermal units to melt one pound of ice. This is very considerable, and causes a downward current of the sea water and what little fresh water has been melted from the ice, so that with a large iceberg the relatively warm water of the sea is flowing from all sides towards the iceberg, and as it comes in contact, it is cooled, sinks, and other water is drawn into its place. Thus the iceberg is constantly being diminished in size, but it does not chill the surface of the water to any considerable extent. If the water about an 


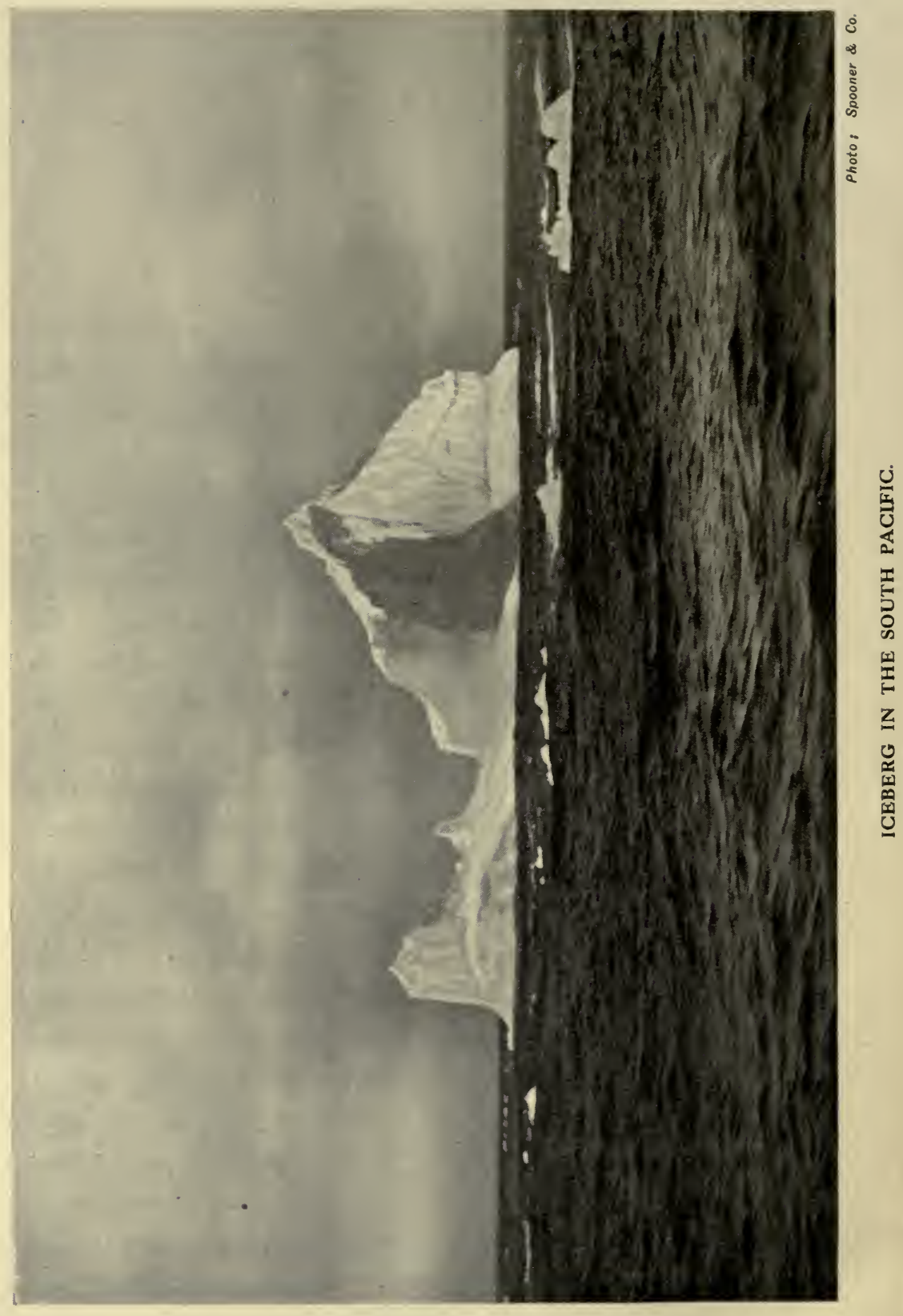




\section{Icebergs}

iceberg is colder than the surrounding water, it will certainly sink, and its place be taken by other water which has not been chilled. It will, therefore, be seen that the testing of the water at any considerable distance from an iceberg can be of little or no use.

With the air, however, it is quite different. The iceberg is never moving as relates to the water, it is always travelling with the water and at the same speed, but the air is always travelling as relates to the iceberg. The result is that a very large quantity of air is chilled by passing over the iceberg, and this forms a bank of air at the leeward of a greater density than the surrounding air, and this of itself is capable of reflecting sound or the kind of vibrations which I employ in my apparatus.

I am very strongly of the opinion that the thermometer, either in the air or in the water, can be of very little use, whereas my apparatus not only detects the presence of an iceberg, but it indicates its approximate direction from the ship, and measures the distance with a high degree of accuracy. Moreover, my apparatus lends itself admirably for transmitting messages, providing the distance is not greater than twenty miles.

Suppose two ships, each provided with my apparatus, should wish to communicate, it is only necessary that the recording apparatus should be turned in the direction of the ship and the mechanism allowed to feed out the strip of paper. We should then be able to dispatch and receive messages, using the Morse code-a short blast for the dot and a long blast for a dash. In like manner a ship would be able to communicate with the shore, providing the distance was not too great. 


\section{A New System for Preventing Collisions at Sea}

In conclusion, I would say that, as steamships are always provided with plenty of steam power, there is no reasonable limit to the size of the apparatus that may be used. It may be possible to send out a series of pulsations that will travel over a distance of 100 miles and be received by the delicate apparatus which I prefer to call a "recorder."

In this little booklet, I have only shown devices that are easily understood by the unscientific. For producing the primary vibrations on the ship I use a modified form of a siren, with certain improvements that make it much more powerful than those now in use. For receiving the echo, I have shown two separate devices-one that rings a series of bells of assorted sizes according to the intensity of the echo, and another for recording the echo and showing, in a very graphic manner, the distance that the object is from the ship. In both of these, I employ a simple diaphragm stretched over the head of a cylinder after the manner of a drum, and it is the vibrations of these diaphragms that open and close the electrical circuit that rings the bells in the one case, and in the other case produces zigzag lines on a strip of paper.

Full and complete working drawings have been made of all of these devices, and, of course, these large, coloured drawings are much easier to understand than the very small illustrations which form part of this booklet. However, if interested parties wish to see the large drawings, I am prepared to show them.

The apparatus will work exactly as described with the devices already designed, but I am not going to rest at this point. I shall shortly produce a recording instrument with 


\section{Icebergs}

a selective power that will not receive any vibrations except those due to the echo of the blast sent out. This will eliminate all noises due to the ship and the sea, and produce a very clean record. 




\section{Experiments without Cruelty.}

It is quite possible that what I have written will lead investigators to make experiments on Bats. I therefore suggest how these experiments may be conducted without cruelty.

We all know that if we capture a wild bird and liberate it in a large room with closed windows, it makes a wild and furious rush for what its senses tell it is an opening through which it can escape; its eyes do not reveal the presence of glass. The result is, a broken neck and instant death.

Suppose now that we make the same experiment with a Bat. Before the Bat is liberated it does not perceive the glass, it simply appears to be an opening through which it can escape, exactly as was the case with the bird, and like the bird, when liberated it makes a rush to escape. The flapping of the wings brings its sixth sense into action and it soon perceives that it is face to face with a solid wall. It stops short before it touches the glass, but as its eyes tell it that the road is clear it is naturally greatly puzzled and continues to face the glass without touching it for some time. However, it places much more reliance on the sixth sense than on the sense of sight, otherwise its fate would be the same as that of the bird.

Naturalists have made this experiment, and those that will not admit that the Bat possesses a sixth sense will perhaps explain this phenomenon.

The bird found the glass by the sense of feeling, which is defined in the dictionary as "the sense of touch," with fatal results. The Bat found it by a sense which is not possessed by other animals - what shall we call this sense?

\section{HIRAM S. MAXIM.}

377 NORWOOD ROAD,

WEST NORWOOD,

LONDON, S.E. 



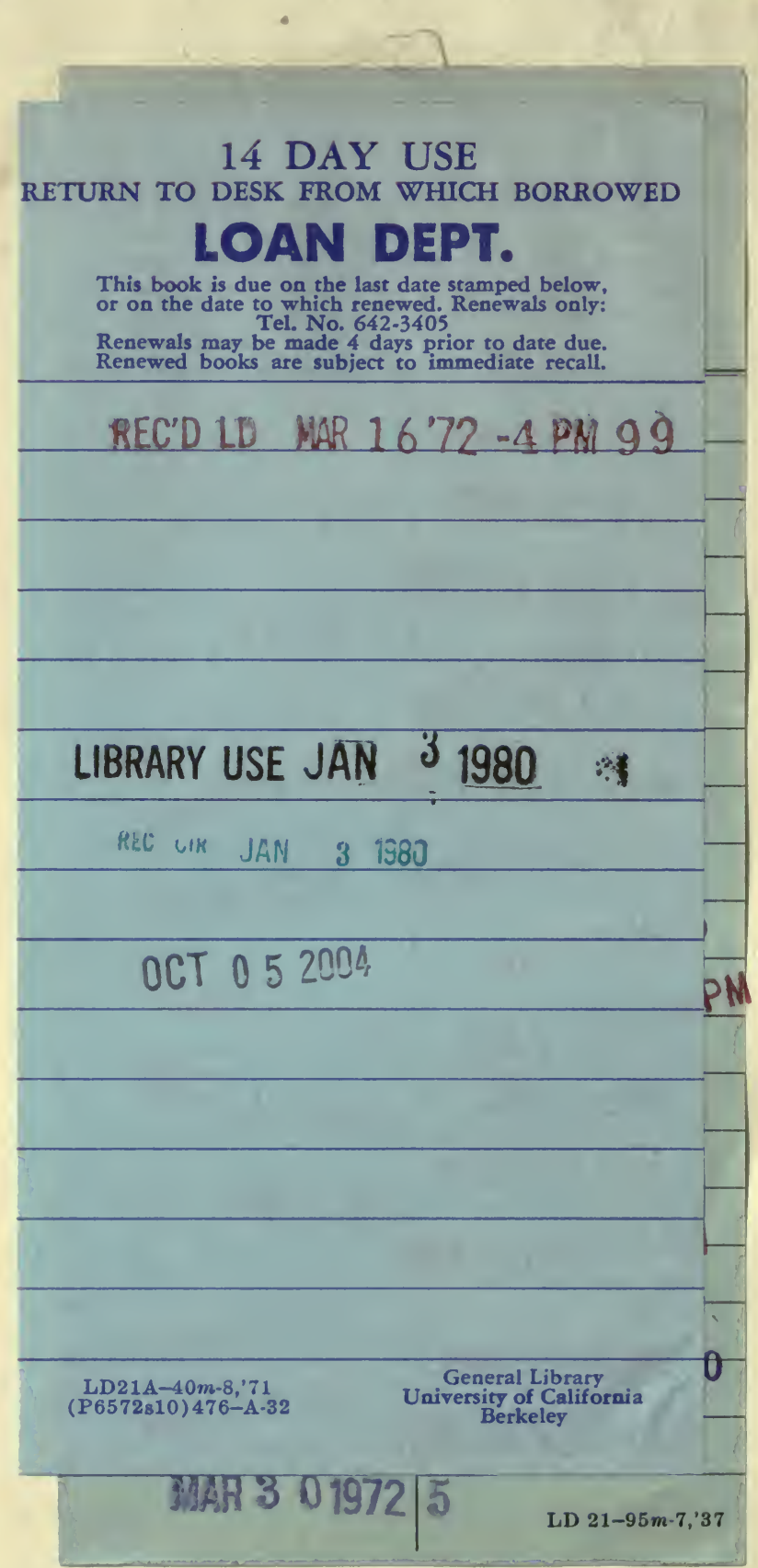




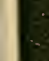

